DOT/FAA/AM-00/28

Office of Aviation Medicine

Washington, D.C. 20591

\section{Controlled Flight Into Terrain: A Study of Pilot Perspectives in Alaska}

Larry L. Bailey

Linda M. Peterson

Kevin W. Williams

Richard C. Thompson

Civil Aeromedical Institute

Federal Aviation Administration

Oklahoma City, Oklahoma 73125

August 2000

Final Report

This document is available to the public through the National Technical Information Service, Springfield, Virginia 22161.

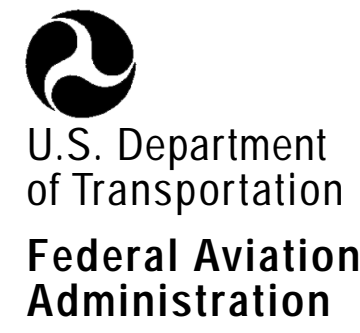




\section{$\mathrm{N} O \mathrm{~T}$ I C E}

This document is disseminated under the sponsorship of the U.S. Department of Transportation in the interest of information exchange. The United States Government assumes no liability for the contents thereof. 
Technical Report Documentation Page

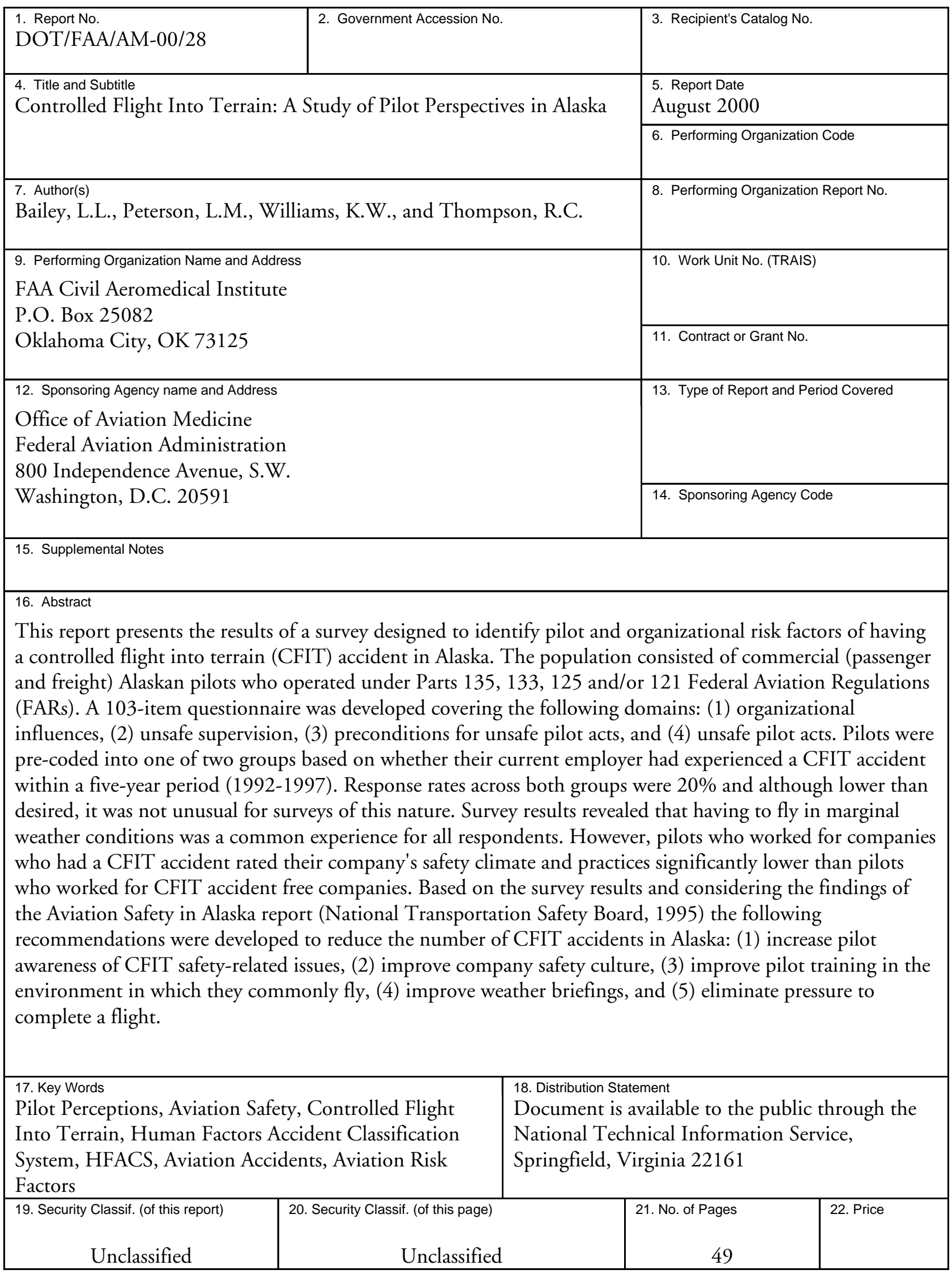

Form DOT F 1700.7 (8-72)

Reproduction of completed page authorized 



\section{ACKNOWLEDGMENTS}

Personnel from the following organizations participated in an inter-agency task force assembled by the Alaska Region Flight Standards Office: Federal Aviation Administration Alaska Region Flight Standards Division; Civil Aeromedical Institute; University of Alaska, Anchorage, and the Alaska Field Station of the National Institute for Occupational Safety and Health.

Special acknowledgments go to the following individuals for their contributions to the successful completion of this research project: Ms. Tara Bergsten, Mr. Gary Childers, Ms. Sally Glasgow, Mr. Gilbert Glover, Mr. Dan Jack, Ms. Janine King, Mr. Jan Manwaring, Ms. Patricia Mattison, Mr. Robert Pearson, Dr. Timothy Thomas, and Ms. Clara Williams. 



\section{Controlled Flight Into Terrain in Alaska: A Study of Pilot Perspectives}

In 1995, the National Transportation Safety Board (NTSB) issued the safety study, Aviation Safety in Alaska, which highlighted two accident types of major consequence: accidents during takeoff and landing, and accidents related to flying under visual flight rules (VFR) into instrument meteorological conditions (IMC). The report states that accidents related to VFR into IMC are less frequent but account for a larger percentage of the fatal accidents, making them the leading safety problem for Alaskan commuter airlines and air taxis (NTSB, 1995).

Seeking to address this critical safety issue, the State of Alaska and the Federal Aviation Administration (FAA) developed several initiatives to reduce aviation fatal accident rates by $80 \%$ by the year 2007 . As part of the overall effort to reduce the number of fatal aircraft accidents in the State of Alaska, an interagency task force was formed to study pilot perceptions of factors relevant to aviation in Alaska. Efforts were focused on the procedures and behaviors of management and employees of Alaskan passenger or freight companies. For the purpose of this research, the terms passenger and freight company are reserved for those companies holding Part 135, 131, 125, and 121 FAA certificates and operating within the State of Alaska. Major airline pilots, the Department of Defense pilots, and pilots employed by the state or federal government were excluded from the study.

The inter-agency task force began with an analysis of the NTSB aircraft accident database for the period January 1, 1990, to December 31, 1998. Data regarding probable causes for each Alaskan commercial aviation accident reported by the NTSB between 1990 and 1998 were reviewed. Accident statistics revealed that controlled flight into terrain (CFIT) was a major factor in the fatality rate in aircraft accidents in Alaska during this period. Of 126 fatality accidents that occurred in Alaska between January 1, 1990, and December 31, 1998, 89 (71\%) involved CFIT. A CFIT accident occurs when an airworthy aircraft, under the control of a pilot, is flown (unintentionally) into terrain, water, or obstacles with inadequate awareness on the part of the pilot (crew) of the impending collision (Wiener, 1977).

In general use, the acronym CFIT refers to a broad spectrum of accidents. These include flights operated under either Instrument Flight Rules (IFR), Visual Flight Rules (VFR) or during transitions from one mode to the other. IFR applies to flights conducted by reference to the aircraft instruments when visibility is reduced. VFR rules apply to flying during which the pilot navigates by maintaining visual contact with objects on the surface.

Due to the specific challenges facing Alaskan aviation, CFIT accidents are limited in the current study to accidents that occurred when aircraft flown under Visual Meteorological Conditions (VMC) encountered Instrument Meteorological Conditions (IMC) and subsequently impacted the terrain. VFR into IMC occurs under the following circumstances: pilots depart for VFR only destinations with the intention of maintaining visual separation from terrain or water and continue flying toward their destination after encountering weather conditions that would normally require flight under IFR. In Alaska, 69 of the 89 fatal CFIT accidents fall into the category described above involving VFR into IMC and account for $77.5 \%$ of all Alaskan CFIT accidents involving fatalities.

All other accident categories, including but not limited to mechanical difficulties, pilot operational error, wind draft or wind shear, runway conditions, foreign objects, and weather and icing conditions at take-off and landing, accounted for only $29 \%$ of the fatal accidents between January 1, 1990, and December 31, 1998. Additionally, the majority of serious injuries are associated with CFIT accidents.

The high fatality rate associated with CFIT events emphasizes the importance of addressing this type of accident and examining the associated risk factors. A substantial reduction of CFIT accidents in Alaska would reduce the number of commercial aviation 
fatalities in that state by up to $70 \%$. Understanding the factors resulting in a pilot flying an airworthy aircraft into terrain can assist in the development of appropriate interventions at multiple levels within the aviation industry and could reduce the number of commercial aviation fatalities.

The NTSB aircraft accident database identified Alaskan companies involved in accidents where NTSB investigators reported VFR to IMC as a contributing factor in the crash. These companies are referred to in the remainder of this report as CFIT companies. Companies without CFIT as an accident causal factor during the same period are referred to as nonCFIT companies. To examine potential differences between CFIT and non-CFIT companies in Alaska, a method of comparing pilot perceptions of the practices, policies, and procedures of their companies and their company's pilots was developed. Identification of differences existing between the two types of companies could heighten awareness of the factors involved in CFIT.

\section{Geographic, Environmental, Airport and Air Route Issues}

Alaska is a vast state, spanning 365 million acres and equal to one-fifth the size of the continental United States. The $49^{\text {th }}$ state is a land of immense geographic diversity, bordered by two oceans and three seas, resulting in more than 33,000 miles of coastline. In the north, Alaska is treeless with tundra, while the Panhandle is lush with temperate rain forests. Alaska also contains North America's highest peak, Mt. McKinley (20,320 feet). The temperature between two locations in Alaska may vary as much as one hundred degrees. Alaska's large landmass, vast mountain ranges, flat marshy tundra, and extensive coastline result in variable climatic zones and weather. Wide areas of poor flight visibility are common. Many VFR destinations have no weather reporting observers or equipment. Pilots base their pre-departure weather evaluations on area forecasts, with inflight updates coming from station agents and what can be observed from the windscreen of their aircraft. In the winter, southern Alaska succumbs to long hours of darkness, and in the far north, night extinguishes day for more than two months. Summer days are long in the northern latitudes. Aviation companies seeking to benefit by the extended daylight may assign pilots to lengthy duty periods.
Although over half of the Alaskan population lives in one of the state's three major cities, Anchorage, Fairbanks, and Juneau (Bureau of the Census, 1992), much of the remaining population lives in remote villages only accessible year-around by aircraft. Commuters and air taxis serve as the main link between these villages and regional hubs, transporting people, goods, and mail. Alaska has approximately 600 published airports and more than 3,000 airstrips (FAA,1996, Flight Tips for Pilots in Alaska, paragraphs 8-10). These airports and airstrips are served by 331 scheduled commuter or charter passenger and freight companies. Sixty-six public airports are equipped to handle IFR arrivals, with the remainder accessible only by flights operated in VMC. A high percentage of flights serving these areas terminate at airports or landing areas with unlighted runways, and many have soft gravel or rutted dirt surfaces. Due to length restrictions, numerous airstrips are limited to only those aircraft able to make approaches and landings. In addition, many aircraft are equipped with floats and land on water surfaces that are visually challenging due to glare and reflection, in addition to being susceptible to both wave fluctuations and wind drafts. Landings under those conditions require special knowledge and skills.

This information presents a picture of Alaska as a unique state with distinctive geographic and environmental features affecting aviation. From this uniqueness emerges an operational requirement that forces pilots to face many difficult decisions about flying each day.

\section{Human Factors Issues}

The 1995 NTSB report investigated the following issues: the operational pressures on pilots and commercial operators to provide reliable air service in an operating environment and aviation infrastructure that are often inconsistent with these demands; the adequacy of weather observing and reporting; the adequacy of airport inspections and reporting airport conditions; the potential effects on safety of current regulations for pilot flight duty and rest time, applicable to commuter and air taxi operations in Alaska; the adequacy of the current instrument flight rules system and enhancements needed to reduce the reliance of Alaska's commuter airline and air taxi operations on visual flight rules; and the needs of special aviation operations in Alaska. 
On the basis of the preceding considerations, researchers determined that CFIT mishaps in Alaska have multiple levels of causality. The concept of multiple levels of causality is a component of the Human Factors Analysis and Classification System (HFACS, Weigmann \& Shappell, 1998), a model developed to analyze and classify human factors associated with aviation accidents.

The HFACS idea that aircraft accidents typically have multiple levels of causality is also known as the "Swiss cheese" model of accident causation and comes from Reason's (1990) work on causes for human error (see Figure 1). In $85 \%$ of all accidents, human error was involved. The human error involvement is not unique to aviation; it applies to any industry (Flight Safety Foundation, 1999).

For an accident to occur, failures have to occur at several different levels of responsibility. Responsibility for an accident typically cannot be placed solely on the pilot because, in the best case scenario, there should be a system in place that would have prevented certain conditions that contributed to the accident. Failures may be attributed to the following: Unsafe Acts, Preconditions for Unsafe Acts, Unsafe Supervision, and/or Organizational Influences.

The HFACS taxonomy defines four levels of causality for accidents, each of which is further subdivided into specific types of failures. Figure 2 demonstrates the
The "Swiss Cheese”' Model of Accident Causation (Reason, 1990)

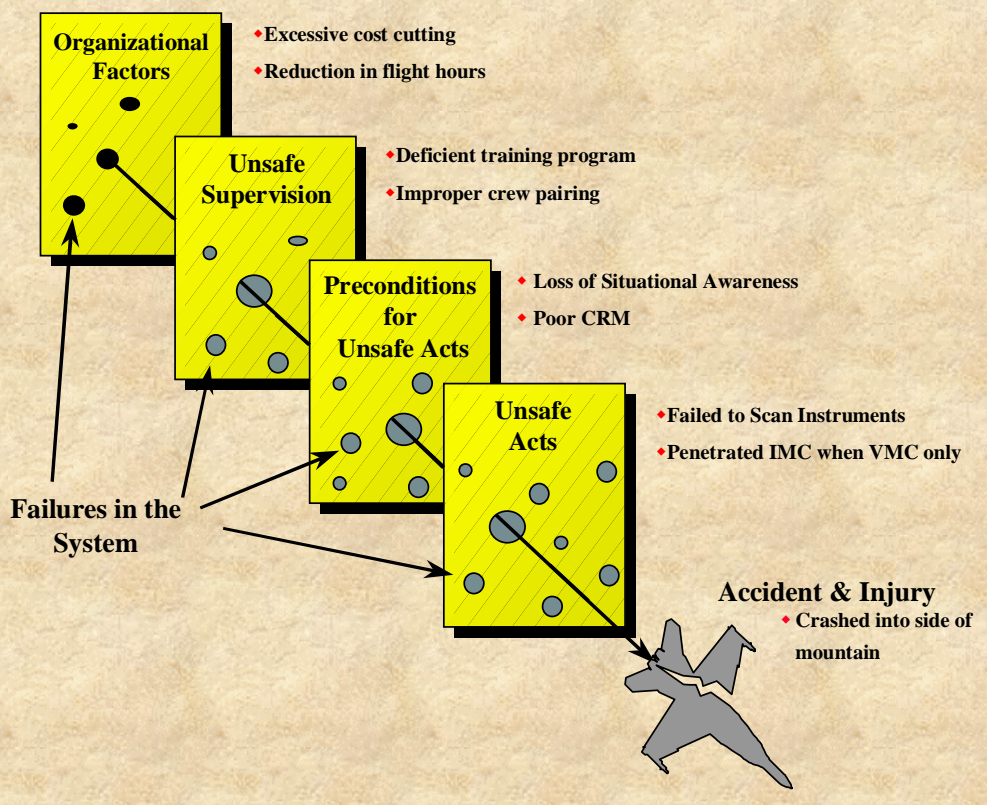

Figure 1: The "Swiss cheese" model of accident causation (Reason, 1990).

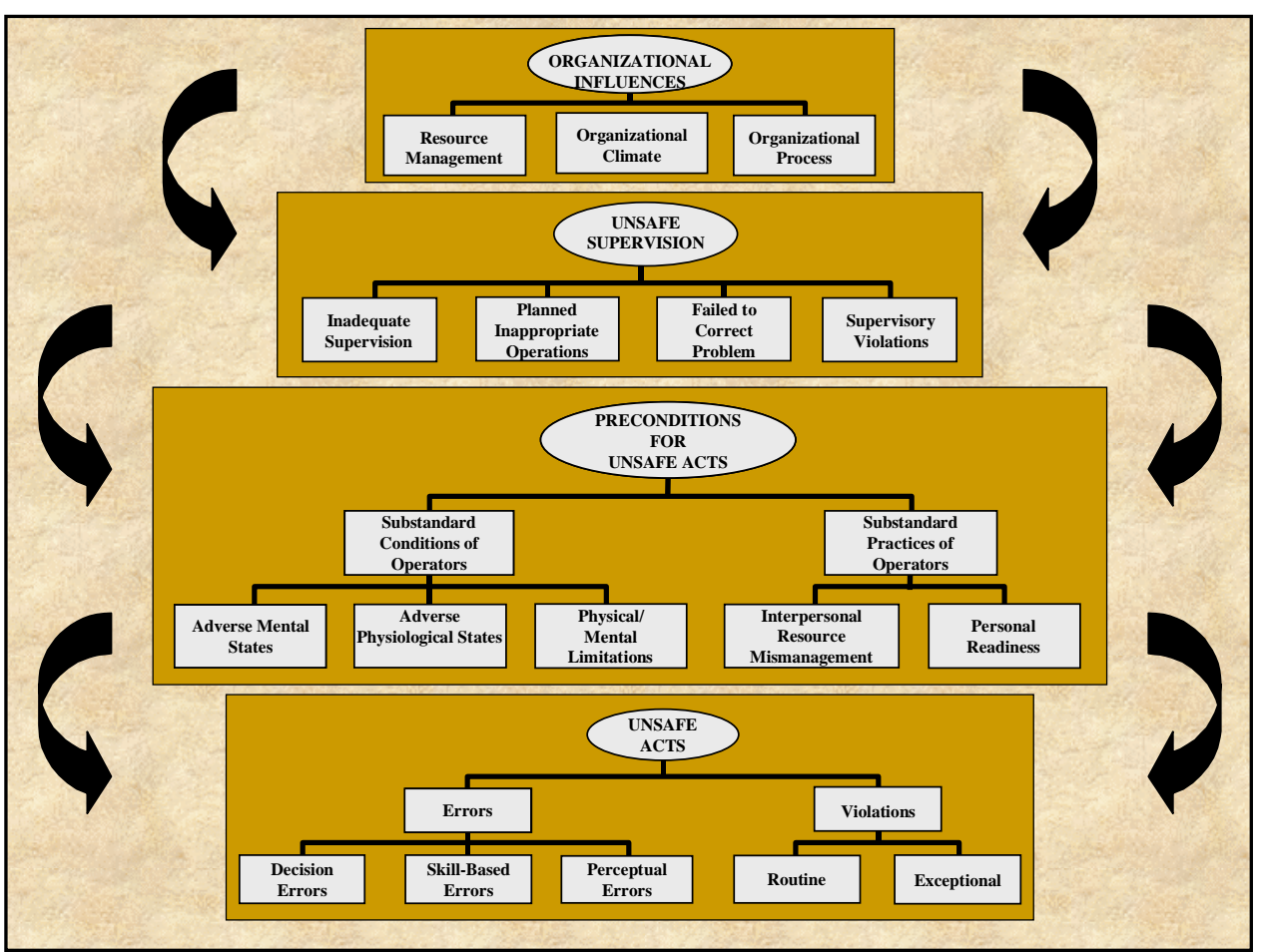

Figure 2: The HFACS taxonomy four categories of the taxonomy and their representative subcategories. (See Appendix A for expanded definitions.) 
The first HFACS level is the Unsafe Act itself. For example, the pilot failed to scan the instruments at a critical time during the flight (Skill-Based Error) or entered instrument conditions unexpectedly (Decision Error) and lost control of the aircraft. Before those events took place, however, certain preconditions for the unsafe acts had to occur.

A second level in the taxonomy identifies Preconditions for Unsafe Acts, which are events that could have led to the unsafe act itself. Fatigue (Substandard Condition of the Operator), for example, could have led to the pilot's poor scanning.

The third level in the taxonomy is Unsafe Supervision. An example of a failure at this level would be inadequate supervision regarding pilot rest requirements and the adverse physiological and mental consequences that could arise from a lack of sleep (Inadequate Supervision).

Underlying Unsafe Supervision, the fourth and final HFACS level involves Organizational Influences. Two examples of failures at this level are a reduction in the training budget (Resource Management) which would eliminate training regarding pilot rest requirements, and an Organizational Climate that condones working beyond the recommended normal work schedule. Some studies stress that CFIT is related to organizational failure (Khatwa \& Roelen, 1998; Maurino, 1993; Weiner, 1977).

Using the HFACS taxonomy summarized above, a survey was devised to assess pilot perceptions of flying conditions in Alaska and evaluate possible differences and similarities between pilots employed by CFIT and non-CFIT companies. These differences could then be examined to formulate recommendations to heighten awareness and reduce CFIT accidents in Alaska.

\section{METHOD}

\section{Questionnaire Development}

For the majority of survey items, item development was based on the taxonomy of the Human Factors Analysis and Classification System (Wiegmann \& Shappell, 1998; see Appendix A). Survey items were generated to measure the extent to which pilot respondents agreed or disagreed that various problematic conditions existed within their company. The majority of the survey questions were structured to allow respondents to answer on a range from Strongly
Disagree to Strongly Agree, with the option of Not Applicable. Questions that were not conducive to agree or disagree ratings used rank order responses; in some instances, categories required a single selection (i.e., demographic information). Due to the difficulty in constructing appropriate items for some of the HFACS domains, different numbers of items were generated for each of the four levels. In all, the following categories were created to assess individual HFACS areas: Unsafe Acts (nine items), Preconditions for Unsafe Acts (20 items), Unsafe Supervision (six items), and Organizational Influences (36 items).

In addition to the items based on the HFACS taxonomy, several items were included for the collection of demographic information. An additional set of items was included to measure pilot perceptions of pilot interactions with FAA personnel and the impact of certain Federal Aviation Regulations (FARs) on flying in Alaska. In all, 87 survey items were generated (see Appendix B).

\section{Pre-testing of the Survey Form}

The survey was pre-tested by 30 personnel from several of the Flight Standards District Offices in Alaska. Pre-testing determined the expected time to complete the survey and whether all of the items were easily understandable by the general pilot population. Changes, additions, and deletions were made to several items in the survey based on information received from the pre-tests.

\section{Survey Population}

Prior to development of the survey, personnel from the Alaska Region Flight Standards Division assembled a list of flight companies in Alaska. Accident data available from the NTSB were used to identify the companies involved in one or more CFIT accidents between January 1, 1992, and September 10,1998 . Of the 330 companies so identified, 301 were designated as non-CFIT and 29 as CFIT companies.

A list of pilots working in Alaska was generated using information on pilot medical certification contained at the Civil Aeromedical Institute (CAMI) in Oklahoma City. All pilots holding a class II medical certificate and living in Alaska were identified. The Alaskan Region Flight Standards Division generated a list of pilots working in Alaska but living out-of-state. These lists were combined and, when possible, employers were identified using the medical certification 
database at CAMI. Pilots working for major airlines were eliminated from the study, as well as military and government pilots. A total of 3,237 pilots were identified to receive the survey.

When appropriate employer information was available, pilots were identified as belonging either to the non-CFIT group or the CFIT group, and the survey they received was coded as a non-CFIT or CFIT survey. When employer information was not available, surveys were coded simply as Other. The survey provided respondents the opportunity to identify their employer. Specific employer information was not kept, and surveys did not contain information regarding the personal identification of the pilots. Returned surveys could be identified as belonging to the non-CFIT or CFIT group but could not be traced to a specific pilot, so the anonymity of the respondent was assured. A total of 680 surveys were coded as nonCFIT; 186 were coded as CFIT; and 2,371 were coded as Other.

\section{Survey Procedure}

One week prior to the distribution of the surveys, an introductory letter was sent to the survey population explaining the need for and purpose of the survey. It gave a broad overview of the types of items contained in the survey and included a request for cooperation, particularly for some of the more sensitive issues covered by the survey. The letter ended with a promise to advise participants of the recommendations developed as a result of the survey analysis. Surveys were mailed the following week. Each survey was accompanied by a cover letter, similar in scope and content to the letter of introduction. Approximately one month following the survey mail out, a follow-up letter was mailed. The letter encouraged respondents to complete and return their surveys.

\section{RESULTS}

\section{Return Rates}

Of the 3,237 surveys distributed, a total of 491 were returned, giving an overall response rate of approximately $15 \%$. While low, this return rate is similar to, or better than, that obtained for other surveys in the Alaskan region (Driskill, Wiessmuller, Quebe, Hand, \& Hunter, 1997; Joseph, Jahns, Nendick, \& St. George, 1999; Rakovan, Wiggins, Jensen, \& Hunter, 1999). Of the 680 non-CFIT surveys, 134 were returned, for a return rate of approximately $20 \%$. Of the 186 CFIT surveys, 37 were returned, also giving a return rate of approximately $20 \%$. Of the 2,371 Other surveys, 320 were returned, (approximately 14\%).

The last item on the survey requested respondents to identify their employing flight company. If the respondent answered this question, and the company was designated as non-CFIT or CFIT group, the survey was coded as either a non-CFIT or CFIT survey. One hundred and thirty-four surveys were identified as non-CFIT or CFIT using this information. Forty-three surveys were dropped because respondents indicated that they worked either for the military or for a major airline. After re-coding and elimination, 234 surveys were identified as nonCFIT surveys, 71 surveys as CFIT surveys, and 143 surveys as Other surveys. Other was not used for further analysis.

Given the low response rates and small sample sizes, the reader is cautioned about generalizing the results of this survey to the broader Alaska population. The lower the response rates, the more uncertainty there is about how well the results will generalize to the target population. Thus, the reader is advised to seek confirmation from other sources (e.g., accident reports or articles) before using the results of this survey to guide policy and decision making.

\section{Survey Item Analysis}

The survey items were analyzed in two ways. First, a descriptive analysis of the item response distributions was conducted for CFIT and non-CFIT company pilots. Next, the response distributions of CFIT and non-CFIT company pilots were statistically compared using non-parametric Mann-Whitney and chisquare tests.

Graphical displays of item response distributions were examined to determine the general shape and frequency of responses. Reported in Appendix B are item sample size, mean, and standard deviation. An additional statistic, percentage disagree and percentage agree, was also included to assist the reader in interpreting item distributions. The percentages were computed by excluding respondents expressing a slight opinion (the middle two rating options; Slightly Agree or Slightly Disagree), and using only respondents who disagreed (combination of Disagree and Strongly Disagree), or agreed (combination of Agree 
and Strongly Agree) with an item. By reporting data in this way, greater attention was given to respondents with more definite opinions.

It was determined that mean scores would not be the appropriate statistic for comparing responses of CFIT and non-CFIT company pilots. Instead, a statistic was needed to determine whether CFIT and non-CFIT company pilots differed in their overall response for a given item. For all items employing a rating scale, the Mann-Whitney test was chosen because it determines whether one population has larger values than the other, regardless of the shape of the response distribution. Using the Mann-Whitney test, 19 items yielded significant differences.

Several survey items required respondents to respond in a check-box-like manner or to rank-order their responses. In these instances, a chi-square test of significance was used to determine whether pilots from non-CFIT companies responded differently, compared with pilots from CFIT companies. The chi-square test analyzes the distribution of responses across the number of response options presented. It uses the sample sizes and the number of response options to determine the probability that a given response will be endorsed. This probability is then compared with the actual percentage of respondents who endorsed a given response option. Using the chisquare test, five items yielded significant differences.

Significant differences in either the Mann-Whitney or chi-square tests were found in the following categories of system failures: Organizational Influences, 11 of 36 questions; Unsafe Supervision, 3 of 6 questions; and Preconditions for Unsafe Acts, 5 of 20 questions. As previously mentioned, all categories were not equally represented. The results appear in Table 1 for items tested using the Mann Whitney statistic and in Table 2 for items tested using the chisquare statistic. To aid the reader in interpreting the results, the percentage of disagreement and agreement are provided, rather than mean scores.

Based on the results presented in Tables 1 and 2 in the category of Organizational Influences, items 60 and 61, which refer to Resource Management (see Figure 2 for HFAC categories and subcategories), show that pilot perceptions differed concerning the age of their company's aircraft, with non-CFIT companies having older aircraft (21-25) than CFIT companies (16-20) (item 61). The perceptions of maintenance provided by a company also differed, with significantly more non-CFIT company pilots agreeing that their company provided sufficient maintenance in the areas of basic flight instruments, navigation instruments, and communication equipment, compared with CFIT company pilots (item 60).

The category of Organization Influences, (subcategory Organizational Climate), indicated differences in pilot perceptions in the areas of pilot morale, safety issues, and final pre-departure go-no-go decisions. More non-CFIT company pilots rated their company's safety climate and practices as safety-oriented than did CFIT pilots, with percentages ranging from 44 to $67 \%$ (items 17, 15, 16). Non-CFIT company pilots also agreed by a greater percentage that their company's morale is high (item 11). Significantly more CFIT company pilots indicated they rely on a flight follower or dispatcher for the final pre-departure go-nogo decisions than did non-CFIT company pilots (item 63).

In the category of Organizational Influences, (subcategory Organizational Process), differences were found between the perceptions of non-CFIT company and CFIT company pilots in the areas of safety, safety awards, and the use of station agents for weather reporting during pre-departure weather determinations. Significantly more non-CFIT company pilots considered their company's safety practices to be better than CFIT pilot companies (item 66) and believed they have more opportunity to make safety recommendations (item 31). The data also reflected that more non-CFIT company pilots agreed that safety awards are used to promote safe flying (item 26). Significantly fewer non-CFIT company pilots reported using station agents for weather reporting services during pre-departure weather evaluations (item 67).

In the category of Unsafe Supervision, (subcategory Inadequate Supervision), items 33 and 34 indicated that non-CFIT company pilots agreed that their company was more cognizant of their frame of mind and physical fitness than CFIT company pilots. In the category of Unsafe Supervision, (subcategory Failed to Correct Problem), non-CFIT pilots agreed that they were more likely to encounter repercussions from flying through weather below legal VFR.

Preconditions for Unsafe Acts, (subcategory Substandard Conditions), indicated significantly fewer non-CFIT company pilots agreed that safety would improve if the visibility requirement for special VFR 
Table 1

Statistically significant items based on Mann-Whitney test of significance.

\begin{tabular}{|c|c|c|c|}
\hline Item & Company & \% Disagree & \% Agree \\
\hline \multicolumn{4}{|l|}{ Organizational Influences } \\
\hline 11. In my company pilot morale is high. & $\begin{array}{l}\text { NON-CFIT } \\
\text { CFIT }\end{array}$ & $\begin{array}{l}24.9 \\
37.7\end{array}$ & $\begin{array}{l}49.8 \\
31.9\end{array}$ \\
\hline 15. My company does all that it can to prevent accidents. & $\begin{array}{l}\text { NON-CFIT } \\
\text { CFIT }\end{array}$ & $\begin{array}{l}14.1 \\
15.9\end{array}$ & $\begin{array}{l}66.5 \\
50.7\end{array}$ \\
\hline 16. My company does not cut corners where safety is concerned. & $\begin{array}{l}\text { NON-CFIT } \\
\text { CFIT }\end{array}$ & $\begin{array}{l}14.1 \\
14.5\end{array}$ & $\begin{array}{l}64.8 \\
43.5 \\
\end{array}$ \\
\hline 17. My company considers the safety of its pilots as its top priority. & $\begin{array}{l}\text { NON-CFIT } \\
\text { CFIT }\end{array}$ & $\begin{array}{l}16.8 \\
17.4\end{array}$ & $\begin{array}{l}59.7 \\
46.4\end{array}$ \\
\hline 26. In my company, safety awards are used to promote safe flying. & $\begin{array}{l}\text { NON-CFIT } \\
\text { CFIT }\end{array}$ & $\begin{array}{l}63.6 \\
79.3\end{array}$ & $\begin{array}{l}23.0 \\
12.1\end{array}$ \\
\hline $\begin{array}{l}\text { 31. My company provides me with opportunities to make safety } \\
\text { recommendations. }\end{array}$ & $\begin{array}{l}\text { NON-CFIT } \\
\text { CFIT }\end{array}$ & $\begin{array}{r}8.5 \\
18.8\end{array}$ & $\begin{array}{l}73.2 \\
56.5\end{array}$ \\
\hline $\begin{array}{l}\text { 61. The average age of the aircraft my company uses is } \\
\text { (Disagree/Agree does not apply). Range: } 1 \text { yr. to more than } 25 \mathrm{yrs} \text {. }\end{array}$ & $\begin{array}{l}\text { NON-CFIT } \\
\text { CFIT }\end{array}$ & \multicolumn{2}{|l|}{$\begin{array}{l}21-25 \mathrm{yrs} . \\
16-20 \mathrm{yrs} .\end{array}$} \\
\hline $\begin{array}{l}\text { 66. My company's safety practices are (Disagree/Agree does not apply; } \\
\text { higher score is better) range: bottom of industry to top of } \\
\text { industry. }\end{array}$ & $\begin{array}{l}\text { NON-CFIT } \\
\text { CFIT }\end{array}$ & \multicolumn{2}{|l|}{$\begin{array}{ll}3.67 & \text { mean } \\
3.19 & \text { mean }\end{array}$} \\
\hline \multicolumn{4}{|l|}{ Unsafe Supervision } \\
\hline $\begin{array}{l}\text { 33. Before each flight, my company makes sure that pilots have the } \\
\text { right frame of mind for flying. }\end{array}$ & $\begin{array}{l}\text { NON-CFIT } \\
\text { CFIT }\end{array}$ & $\begin{array}{l}43.4 \\
53.7\end{array}$ & $\begin{array}{l}26.5 \\
13.4\end{array}$ \\
\hline $\begin{array}{l}\text { 34. Before each flight, my company makes sure pilots are physically fit } \\
\text { to fly (e.g., free from the adverse effects of fatigue, medications) }\end{array}$ & $\begin{array}{l}\text { NON-CFIT } \\
\text { CFIT }\end{array}$ & $\begin{array}{l}40.9 \\
52.2\end{array}$ & $\begin{array}{l}33.6 \\
16.4\end{array}$ \\
\hline $\begin{array}{l}\text { 68. The first time my company discovered I flew through weather } \\
\text { below legal VFR, they would: (Disagree/Agree does not apply; } \\
\text { higher score is more severe) range: severity of disciplinary action }\end{array}$ & $\begin{array}{l}\text { NON-CFIT } \\
\text { CFIT }\end{array}$ & \multicolumn{2}{|l|}{$\begin{array}{ll}.77 & \text { mean } \\
1.53 & \text { mean }\end{array}$} \\
\hline \multicolumn{4}{|l|}{ Preconditions for Unsafe Acts } \\
\hline $\begin{array}{l}\text { 38. In Alaska, safety would improve if the visibility requirement for } \\
\text { special VFR (conducted under FAR Part 135) was increased to } 2 \\
\text { miles when operating under a ceiling of less than } 1000 \text { feet. }\end{array}$ & $\begin{array}{l}\text { NON-CFIT } \\
\text { CFIT }\end{array}$ & $\begin{array}{l}51.7 \\
39.7\end{array}$ & $\begin{array}{l}31.7 \\
47.1\end{array}$ \\
\hline $\begin{array}{l}\text { 43. In Alaska, during periods of extended daylight, pilot and co-pilot } \\
\text { aircrews fly over } 10 \text { hours per day. }\end{array}$ & $\begin{array}{l}\text { NON-CFIT } \\
\text { CFIT }\end{array}$ & $\begin{array}{l}46.6 \\
66.2 \\
\end{array}$ & $\begin{array}{l}34.5 \\
16.9\end{array}$ \\
\hline $\begin{array}{l}\text { 44. It is hard for Alaskan passenger and freight pilots to maintain a } \\
\text { consistent sleep schedule. }\end{array}$ & $\begin{array}{l}\text { NON-CFIT } \\
\text { CFIT }\end{array}$ & $\begin{array}{l}31.3 \\
46.5 \\
\end{array}$ & $\begin{array}{l}43.6 \\
26.8 \\
\end{array}$ \\
\hline $\begin{array}{l}\text { 45. In Alaska, during periods of extended daylight, a single-pilot } \\
\text { aircrew flies over } 8 \text { hours per day. }\end{array}$ & $\begin{array}{l}\text { NON-CFIT } \\
\text { CFIT }\end{array}$ & $\begin{array}{l}49.0 \\
65.7 \\
\end{array}$ & $\begin{array}{l}28.3 \\
13.4 \\
\end{array}$ \\
\hline $\begin{array}{l}\text { 46. Alaskan passenger and freight pilots understand how the time of } \\
\text { day can affect their flying performance. }\end{array}$ & $\begin{array}{l}\text { NON-CFIT } \\
\text { CFIT }\end{array}$ & $\begin{array}{l}8.8 \\
7.1 \\
\end{array}$ & $\begin{array}{l}69.6 \\
52.9 \\
\end{array}$ \\
\hline \multicolumn{4}{|l|}{ Demographic Information } \\
\hline $\begin{array}{l}\text { 70. I am } \quad \text { years old. (Disagree/Agree does not apply) range: } 18 \\
\text { years to over } 50 \text { years }\end{array}$ & $\begin{array}{l}\text { NON-CFIT } \\
\text { CFIT }\end{array}$ & \multicolumn{2}{|l|}{$\begin{array}{l}46-50 \text { yrs. } \\
41-45 \text { yrs. }\end{array}$} \\
\hline $\begin{array}{l}\text { 71. I've flown in Alaska a total of___ years. (Disagree/Agree does } \\
\text { not apply) range: } 1 \text { year to } 56 \text { years }\end{array}$ & $\begin{array}{l}\text { NON-CFIT } \\
\text { CFIT }\end{array}$ & \multicolumn{2}{|c|}{$\begin{array}{|ll|}18.56 \text { yrs mean } \\
15.07 \text { yrs } & \text { mean } \\
\end{array}$} \\
\hline $\begin{array}{l}\text { 74. My total number of commercial rotary hours is (Disagree/Agree } \\
\text { does not apply) range: } 0 \text { hours to } 17,000 \text { hours }\end{array}$ & $\begin{array}{l}\text { NON-CFIT } \\
\text { CFIT }\end{array}$ & \multicolumn{2}{|c|}{$\begin{array}{ll}2970 \text { hrs. mean } \\
1129 \text { hrs. } \\
\end{array}$} \\
\hline
\end{tabular}

Note: The percentages were computed by excluding respondents expressing a slight opinion (the middle two ratings options: slightly agree or slightly disagree), and using only respondents who disagreed (combination of disagree and strongly disagree), or agreed (combination of agree and strongly agree) with an item. 
Table 2

Statistically significant items based on chi-square test of significance.

\begin{tabular}{|c|c|c|}
\hline Item & \% Non-CFIT Pilots & \% CFIT Pilots \\
\hline \multicolumn{3}{|l|}{ Organizational Influence } \\
\hline $\begin{array}{l}\text { 60. My company provides sufficient maintenance on each } \\
\text { of the following aircraft components } \\
\text { Basic flight instruments } \\
\text { Navigation instruments } \\
\text { Communication equipment }\end{array}$ & $\begin{array}{l}86.3 \\
78.6 \\
86.3\end{array}$ & $\begin{array}{l}69.0 \\
64.8 \\
66.2\end{array}$ \\
\hline $\begin{array}{l}\text { 63. Who makes the final pre-departure go-no-go decision } \\
\text { Flight follower or dispatcher }\end{array}$ & 12.4 & 23.9 \\
\hline $\begin{array}{l}\text { 67. My company uses each of the following weather } \\
\text { reporting services during pre-departure weather } \\
\text { evaluations: Stations Agents }\end{array}$ & 46.2 & 60.6 \\
\hline \multicolumn{3}{|l|}{ Demographic Information } \\
\hline $\begin{array}{l}\text { 72. I fly in Alaska during the following months } \\
\text { November } \\
\text { December } \\
\text { January } \\
\text { February } \\
\end{array}$ & $\begin{array}{l}85.5 \\
82.9 \\
83.3 \\
84.2\end{array}$ & $\begin{array}{l}97.2 \\
95.8 \\
95.8 \\
94.4\end{array}$ \\
\hline $\begin{array}{l}\text { 75. I hold the following airman's certificates and ratings } \\
\text { Airline Transport Pilot }\end{array}$ & 61.5 & 80.3 \\
\hline $\begin{array}{l}\text { Please indicate the certificate holder you work for: } \\
\text { Part } 135\end{array}$ & 59.0 & 88.7 \\
\hline
\end{tabular}

Note: The percentages were computed by excluding respondents expressing a slight opinion (the middle two ratings options: slightly agree or slightly disagree), and using only respondents who disagreed (combination of disagree and strongly disagree), or agreed (combination of agree and strongly agree) with an item.

(conducted under FAR Part 135) was increased to two miles when operating under a ceiling of less than 1,000 feet (item 38).

The HFACS category of Preconditions for Unsafe Acts, (subcategory Adverse Mental Conditions), indicated the following differences in non-CFIT company and CFIT company pilot perceptions: Pilots flying for non-CFIT companies agreed that they have a better understanding of how the time of day can affect their flying performance (item 46). Non-CFIT company pilots report flying longer hours for both single pilot and for pilot co-pilot crews (items $43 \&$ 45). Additionally, non-CFIT company pilots report having greater difficulty maintaining a consistent sleep schedule (item 44).

Demographic differences were also noted, including: a greater percentage of pilots who fly for CFIT companies do so under Part 135 rules, have an Airline Transport certificate (item 75), and fly during the months of November, December, January, and February (item 72). Pilots flying for non-CFIT companies are, on average, older (item 70), have more years of experience flying in Alaska (item 71), and have more hours flying commercial rotary aircraft (item 74).

\section{DISCUSSION AND RECOMMENDATIONS}

The primary purpose of developing the survey was to create an instrument with the potential to differentiate between the perceptions of pilots who flew for CFIT companies and those who flew for non-CFIT companies. Based on the profile that emerged from the results, it is clear that this objective was accomplished. The survey distinguished the perceptions of pilots of non-CFIT and CFIT companies in the following areas: Organizational Influences, Preconditions for Unsafe Acts, and Unsafe Supervision.

Data analyzed from the study indicate lower CFIT company pilot agreement in the crucial areas of safety practices and overall safety climate of their company than pilot's of non-CFIT companies. In the event 
that CFIT companies create a more positive safety climate and improve their safety practices, it is likely that they will also reduce their risk of CFIT accidents.

In addition, the data reflect that among non-CFIT company pilots, the ranking of a company priority for safety practices and overall safety climate ranges from a low of $23 \%$ to a high of $73 \%$. This range indicates room for improvement in safety policies, procedures and practices of non-CFIT as well as CFIT companies.

Based on the survey results and considering the findings of the Aviation Safety in Alaska report (National Transportation Safety Board, 1995) the following recommendations were developed to reduce the number of CFIT accidents in Alaska: (1) increase pilot awareness of CFIT safety-related issues, (2) improve company safety culture, (3) improve pilot training in the environment in which they commonly fly, (4) improve weather briefings, and (5) eliminate pressure to complete a flight.

An assessment to determine the efficacy of the suggested interventions is essential to ascertain changes in pilot perceptions in the four HFACS categories, with an emphasis on exploring changes in safety practices and safety climate.

The results of this survey research should not be viewed in isolation of other related research on this topic. In this case, a number of studies have examined the issue of why CFIT accidents happen and what can be done to prevent them. A recent study (General Aviation Controlled Flight Into Terrain, 1999), conducted by a FAA Joint Safety Analysis Team reviewed the CFIT records of U.S. general aviation during the past five years. Many of the current survey's findings support the recommendations that emerged from the safety team, adding further evidence for the validity of the survey and its value as an organizational assessment tool.

\section{REFERENCES}

Bureau of the Census. United States Department of Commerce (1992). Population count in the 1990 U.S. census: statistical abstract of the United States, $112^{\text {th }}$ ed. Washington, DC: U.S. Government Printing Office.

Driskill, W.E., Weissmuller, J.J., Quebe, J.C., Hand, D.K., \& Hunter, D. (1997). The use of weather information in aeronautical decision-making: II. U.S. Department of Transportation, Federal Aviation Administration, Office of Aviation Medicine, Washington, D.C. Report \# DOT/FAA/ AM-97/23. NTIS \# ADA340406.

Federal Aviation Administration Alaskan Region (1996). Flight Tips for Pilots in Alaska, [Online] Available: http://www.alaska.faa.gov/flytoak/flttips1.htm [1998, December 2].

Federal Aviation Administration Joint Safety Analysis Team (1999). General Aviation: Controlled flight into Terrain. Washington, DC.

Flight Safety Foundation. (No date) [Online] Available: http://www.flightsafety.org/priorities.html. [1999, December 1].

Hunter, D.R. (1995). Airmen research questionnaire: Methodology and overall results. U.S. Department of Transportation, Federal Aviation Administration, Office of Aviation Medicine, Washington, D.C. Report \# DOT/FAA/AM-95/27.

Joseph, K.M., Jahns, D.W., Nendick, M.D., \& St. George, R. (1999). A usability survey of GPS avionics equipment: Some preliminary findings. U.S. Department of Transportation, Federal Aviation Administration, Office of Aviation Medicine, Washington, D.C. Report \# DOT/FAA/AM-99/ 9. NTIS \# ADA362193INZ.

Khatwa R., \& Roelen, A.L.C. (1998). An analysis of controlled-flight-into-terrain accidents of commercial operators, 1988 through 1994. Flight Safety Digest, 165-212. 
Maurino, D. (1993). Efforts to reduce CFIT accidents should address failures of the aviation system itself. ICAO Journal, May.

National Transportation Safety Board (1995). Aviation safety in Alaska: Safety study. (NTSB/SS-95/03). Washington, DC.

Rakovan, L., Wiggins, M.W., Jensen, R.S., \& Hunter, D.R. (1999). A survey of pilots on the dissemination of safety information. U.S. Department of Transportation, Federal Aviation Administration, Office of Aviation Medicine, Washington, D.C. Report \# DOT/FAA/AM-99/7. NTIS \# ADA361233INZ.
Reason, J. (1990). Human Error. Cambridge, Cambridge University Press.

Weigmann, D.A. \& Shappell, S.A. (1998). A human factors approach to accident analysis and prevention. National Transportation Board of Safety. Washington, DC: Author.

Weiner, E.L. (1977) Controlled flight into terrain: System induced accidents. Human Factors Journal, 19. 


\section{APPENDIX A}

\section{Taxonomy of Unsafe Operations (Shappell \& Wiegmann, 1997)}

\section{ORGANIZATIONAL INFLUENCES}

\section{Resource Management}

Human - refers to the management of operators, staff, and maintenance personnel. Issues that directly influence safety include selection (including background checks), training, and staffing/manning.

Monetary - refers to the management of nonhuman resources, primarily monetary resources. Issues such as excessive cost-cutting, a lack of funding for proper and safe equipment and resources have adverse effects on operator performance and safety.

Equipment/Facility - refers to issues related to equipment design, including the purchasing of unsuitable equipment, inadequate design of work spaces, and failures to correct known design flaws. Management should ensure that human factors engineering principles are known and utilized and that specifications for equipment and work space design are identified and met.

\section{Organizational Climate}

Structure - refers to the formal component of the organization. The "form and shape" of an organization are reflected in the chain-of-command, delegation of authority and responsibility, communication channels, and formal accountability for actions. Organizations with maladaptive structures (i.e., do not optimally match to their operational environment or are unwilling to change), will be more prone to accidents and "will ultimately cease to exits".

Policies - refers to a course or method of action that guides present and future decisions. Policies may refer to hiring and firing, promotion, retention, raises, sick leave, drugs and alcohol, overtime, accident investigations, use of safety equipment, etc. When these policies are ill-defined, adversarial, or conflicting, safety may be reduced.

Culture - refers to unspoken or unofficial rules, values, attitudes, beliefs, and customs of an organization. "The way things really get done around here". Other issues related to culture included organizational justice, psychological contracts, organizational citizenship behavior, esprit de corps, and union/management relations. All these issues affect attitudes about safety and the value of a safe working environment.

\section{Organizational Process}

Operations - refers to the characteristics or conditions of work that have been established by management. These characteristics included operational tempo, time pressures, production quotas, incentive systems, schedules, etc. When set up inappropriately, these working conditions can be detrimental to safety.

Procedures - the official or formal procedures as to how the job is to be done. Examples include performance standards, objectives, documentation, instructions about procedures, etc. All of these, if inadequate, can negatively impact employee supervision, performance, and safety.

Oversight - refers to management's monitoring and checking of resources, climate, and processes to ensure a safe and productive work environment. Issues here relate to organizational self study, risk management, and the establishment and use of safety programs. 


\section{UNSAFE SUPERVISION}

\section{Unforeseen}

Unrecognized Hazardous Operations - can be viewed as a loss of supervisory situational awareness. Though somewhat broad, it includes those instances when unsafe conditions or hazards exist yet go unseen or unrecognized by the untrained or over-tasked supervisor. Selected examples include:

- Medical conditions such as illness or fatigue that adversely effect performance and

- The insidious effects of recent life changes such as divorce, death of a family member, legal difficulties, financial discord, and other personal difficulties.

Inadequate Documentation/Procedures - typical of most systems, particularly new ones where the "bugs" have yet to be worked out.

- Accounting for all possible contingencies through technical specifications, instructions, regulations, and standard operating procedures is an extremely difficult task, at best. As a result, accidents, incidents, and hazards continue to be a common way of identifying deficiencies in existing documentation, often after tragedy has struck.

\section{Known}

Inadequate Supervision - refers to management of the individual on a personal level. It is expected that individuals will receive adequate training, professional guidance, and operational leadership, and that all will be managed appropriately. Unfortunately, supervision may prove inappropriate, improper, or may not occur at all. Regardless, inadequate supervision is viewed as a function of some action, or purposeful inaction by the supervisor.

Planned Inappropriate Operations - refers to management of the individual as an asset among many others (I.e., a "cog in the wheel"). Occasionally, the operational tempo and/or schedule is planned such that individuals are put at unacceptable risk, crew rest is jeopardized, and ultimately performance is adversely affected. Such operations, though arguably unavoidable emergency situations, are unacceptable during normal operations.

Failed to Correct Problem - refers to those instances when deficiencies among individuals, equipment, training or other related safety areas are "known" to the supervisor yet are allowed to continue uncorrected.

Supervisory Violations - refers to those instances when existing rules, regulations, instructions, or standard operating procedures are not adhered to by supervisors when managing assets. Moreover, that it is considered an "intended" act implies a willful disregard for authority. This is quite different from inadvertently or unwittingly violating the rules, considered unrecognized hazardous operations as described earlier.

\section{PRECONDITIONS FOR UNSAFE ACTS}

\section{Substandard Conditions of Operators}

Adverse Mental States - refers to those psychological and/or mental conditions that impact negatively on performance. Principle among adverse mental states are the loss of situational awareness, cognitive effects of sleep loss and circadian dysrhythmia, and other psychological diagnoses that effect safety. Also included in this category are personality traits and pernicious attitudes such as overconfidence, and complacency, and misplaced motivation. 
Adverse Physiological States - refers to those medical or physiological conditions that preclude safe operations. Particularly important to some operational settings are conditions such as: hypoxia, physical fatigue, illness, intoxication, and the myriad of pharmacological and medical abnormalities known to affect performance.

Physical/Mental Limitations - refers to those instances when necessary visual or aural information is not available due to limitations inherent within the sensory system. For instance, in aviation, this most often includes not seeing other aircraft, power lines and other obstacles due to the size or contrast of the object in the visual field. Also included are those instances when time to process information or respond exceeds human capacity (i.e., the individual simply could not physically respond or decide quickly enough to avert the accident). Finally, there may be time when the individuals inherent aptitude or intelligence is incompatible with the characteristics or requirements of the task.

\section{Substandard Practices of Operators}

Interpersonal Resource Management - was created to account for occurrences of poor crew coordination in selected occupational settings. Also included are those instances when individuals directly responsible for the conduct of the operations fail to coordinate and/or supervise operations appropriately. For instance, within aviation this category is reserved for aircrew who function during the flight as aircraft commanders, flight leaders, section leaders, etc. Elements of this category differ from those classified as unsafe supervision, since those generally involve individuals in positions of higher authority detached from the direct conduct of operations.

Personal Readiness - two general issues fall under this category. The first is readiness violations which refer to the disregard for rules, regulations, and instructions that govern the individual's readiness to perform. These include such behaviors as violating crew rest requirements and alcohol restrictions. Both may lead to altered behavioral states and lead to the occurrence of unsafe acts. On the other side of the coin, sometimes aviators exhibit poor judgement when it comes to readiness, but do not necessarily violate existing instructions or standard operating procedures. For example, running 10 miles before piloting an aircraft may impair the physical and mental capabilities of the individual enough to degrade performance and elicit unsafe acts. However, there may be no rules governing such behavior, other than reasonable judgment.

\section{UNSAFE ACTS}

\section{Errors}

Decision errors - these represent intentional behavior that proceeds as intended, yet the chosen plan proves inadequate to achieve the desired outcome. Procedural Decision Errors (Orasanu, 1994), or rule-based mistakes (Rasmussen, 1986) occur during highly structured tasks (If X, then do Y). For example, for most emergency situations, condition-action rules are available as standard procedures. Procedural decision errors often occur when a situation is not recognized or is misdiagnosed and the wrong procedure is performed. However, not all situations have corresponding procedures to deal with them. Therefore, many situations require a choice to be made among multiple response options. Under these circumstances, choice decision errors (Orasanu, 1994), or knowledge-based mistakes (Rasmussen, 1986), may occur, particularly when there is insufficient experience or time to determine which option is best. Finally, sometimes a problem is not well understood and formal procedures and response options are not available. In these situations, the problem is ill-defined and it requires the invention of a novel solution; therefore, individuals must resort to slow and effortful reasoning processes, which may result in problem-solving errors. 
Skill-base Errors - these are errors in the execution of a response that has become highly automated. They are actions that unwittingly deviate from planned behavior, and are generally classified as either attention or memory failures. Attention failures may take the form of a break down in visual scan, inadvertent operation of a control, or a failure to see and avoid. Memory failures may appear as omitted items in a checklist, place losing, or forgotten intentions.

Perceptual Errors - these errors occur when we misrecognize some object or sensory input, for example misjudging distance, altitude or airspeed. Other types of perceptual errors include visual illusions or spatial disorientation where perceptions of the world are not congruent with reality.

\section{Violations}

Routine Violations - tend to be habitual by nature constituting a part of the individual's behavioral repertoire (I.e., driving consistently 5-10 mph faster than allowed by law). Often routine violations are perpetuated by a system that tolerates such departures.

Exceptional violations - on the other hand, are isolated departures from authority not necessarily indicative of an individuals typical behavior pattern nor condoned by management (an isolated instance of driving $105 \mathrm{mph}$ in a $55 \mathrm{mph}$ zone is considered an exceptional violation, not because of its extreme nature, but because its neither typical of the individual not condoned by authority.) 


\section{APPENDIX B}

Summary of Results for

Non-CFIT Company Pilots and CFIT Company Pilots

FAA Civil Aeromedical Institute

Human Resources Research Division

Oklahoma City, OK 73125

In collaboration with:

Dan G. Jack

Omni Corporation

Albuquerque, NM 87107

March 15, 2000 


\section{Guide to Report Content}

Results of the Alaskan Flight Industry Survey are summarized in this report. Presented are item by item comparisons of responses for non-CFIT company pilots and CFIT company pilots. Included in the comparisons are item descriptive statistics, response distributions, and significant findings. Items are grouped based on The Taxonomy of Unsafe Operations (Shappell and Wiegmann, 1997)

\section{Descriptive Statistics}

Descriptive statistics apply to each individual item, independent of any other item.

n Number of valid responses for each pilot group for an item.

Mean Average of all valid responses for each pilot group for an item. Means for selected items are also presented in graphs.

SD Standard Deviation - a measure of dispersion, or spread, of scores around the mean for each pilot group.

\% Disagree These percentages were computed by excluding respondents expressing a slight and opinion (the middle two rating options; slightly agree or slightly disagree) or $\%$ Agree agreed(combination of agree and strongly agree) with an item

\section{Response Distributions}

Where appropriate, response distributions are presented in bar graphs to the right of each item. Distributions are based on the percentage of responses within each response category for each pilot group. Distributions may not sum to 100 due to rounding.

Response distributions for multiresponse items are reported as percentages in tables. For these items, percentages will not sum to 100 because respondents were asked to mark all that apply.

\section{Significant Findings}

All items were tested for significant differences between non-CFIT company pilot and CFIT company pilot groups. Chi square tests were used for multiresponse items or nominal level data. Mann-Whitney tests were used for all other items. The statistical tests were conducted on each item independently of all other items.

sig. Indicates a finding of significant difference between non-CFIT company pilot and CFIT company pilot groups. 


\section{ALASKAN PILOT AND FAA OFFICIAL INTERACTION}

1. In Alaska, FAA inspectors adequately explain the rationale behind the decisions they make.

Descriptive Statistics

$\begin{array}{rrrrrr}\text { Non-CFIT Company Pilots } & 215 & 3.56 & 1.42 & 27.9 & 35.3 \\ \text { CFIT Company Pilots } & 68 & 3.65 & 1.41 & 26.5 & 36.8\end{array}$

2. When interacting with FAA inspectors, Alaskan passenger and freight pilots are allowed to express their point of view.

\begin{tabular}{rrrccc} 
& \multicolumn{5}{c}{ Descriptive Statistics } \\
& n & Mean & SD & \% Disagree & \% Agree \\
Non-CFIT Company Pilots & 219 & 4.06 & 1.27 & 15.1 & 50.2 \\
CFIT Company Pilots & 69 & 4.26 & 1.05 & 7.2 & 55.1
\end{tabular}

3. FAA inspectors use the same evaluation standard for Alaskan passenger and freight pilots.

\begin{tabular}{rrrrcc} 
& \multicolumn{5}{c}{ Descriptive Statistics } \\
& n & Mean & SD & \% Disagree & \% Agree \\
Non-CFIT Company Pilots & 189 & 3.95 & 1.42 & 20.1 & 52.4 \\
CFIT Company Pilots & 62 & 4.06 & 1.30 & 12.9 & 54.8
\end{tabular}

4. FAA inspectors are courteous when interacting with Alaskan passenger and freight pilots.

\begin{tabular}{rrrccc} 
& \multicolumn{5}{c}{ Descriptive Statistics } \\
& n & Mean & SD & $\%$ Disagree & $\%$ Agree \\
Non-CFIT Company Pilots & 220 & 4.50 & 1.12 & 7.3 & 66.8 \\
CFIT Company Pilots & 70 & 4.61 & 0.98 & 4.3 & 70.0
\end{tabular}

${ }^{1}$ significant difference (Chi square) $p<.05$

${ }^{2}$ significant difference (Mann-Whitney) $p<.05$

$\%$ Disagree $=$ Strongly Disagree or Disagree

$\%$ Agree=Strongly Agree or Agree

Response Distribution (percent)
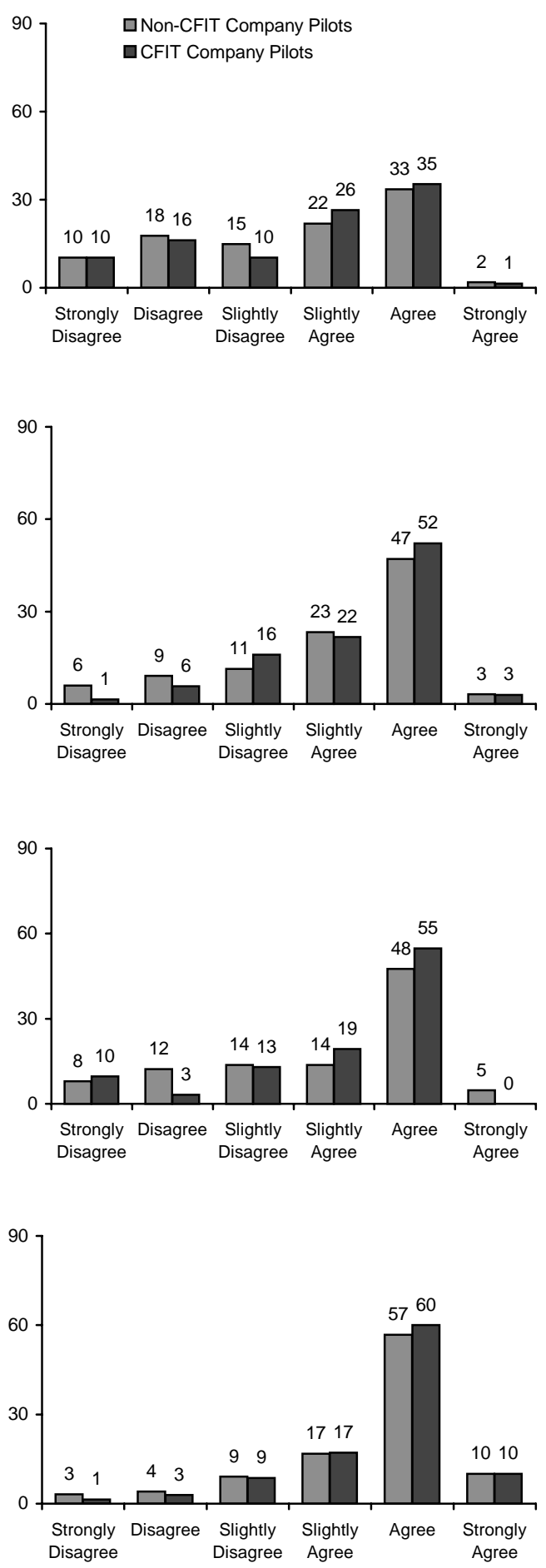
5. Overall, the FAA inspectors treat Alaskan passenger and freight pilots fairly.

\begin{tabular}{rrrccc} 
& \multicolumn{5}{c}{ Descriptive Statistics } \\
& n & Mean & SD & \% Disagree & \% Agree \\
Non-CFIT Company Pilots & 216 & 4.18 & 1.22 & 12.0 & 51.4 \\
CFIT Company Pilots & 67 & 4.39 & 0.98 & 6.0 & 62.7
\end{tabular}

6. If Alaskan passenger and freight pilots followed all aspects of the FARs, they would not be able to get their job done.

\begin{tabular}{rrrccc} 
& \multicolumn{5}{c}{ Descriptive Statistics } \\
& n & Mean & SD & $\%$ Disagree & $\%$ Agree \\
Non-CFIT Company Pilots & 225 & 3.91 & 1.63 & 27.1 & 42.7 \\
CFIT Company Pilots & 71 & 4.03 & 1.59 & 21.1 & 43.7
\end{tabular}

7. Additional exemptions are needed in the FARs so that the rules conform to the reality of Alaskan flight operations.

\begin{tabular}{rrrrccc} 
& \multicolumn{5}{c}{ Descriptive Statistics } \\
& n & Mean & SD & \% Disagree & \% Agree \\
Non-CFIT Company Pilots & 224 & 4.31 & 1.60 & 19.2 & 54.0 \\
CFIT Company Pilots & 71 & 4.20 & 1.53 & 15.5 & 49.3
\end{tabular}

8. The FARs interfere with the profitability of Alaskan passenger and freight operations.

\begin{tabular}{rrrccc} 
& \multicolumn{5}{c}{ Descriptive Statistics } \\
& n & Mean & SD & \% Disagree & \% Agree \\
Non-CFIT Company Pilots & 217 & 3.47 & 1.49 & 35.0 & 29.5 \\
CFIT Company Pilots & 69 & 3.45 & 1.45 & 29.0 & 21.7
\end{tabular}

\section{Response Distribution (percent)}
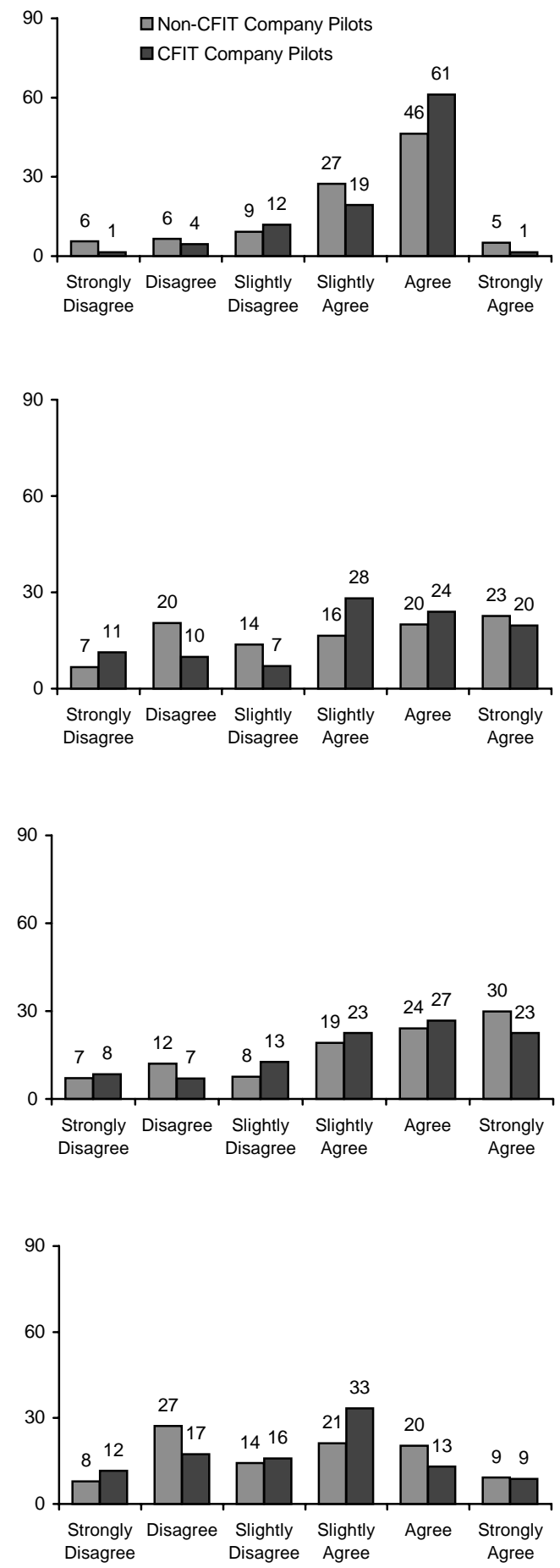

${ }^{1}$ significant difference (Chi square) $\mathrm{p}<.05$

${ }^{2}$ significant difference (Mann-Whitney) $p<.05$

$\%$ Disagree=Strongly Disagree or Disagree

$\%$ Agree=Strongly Agree or Agree 


\section{ORGANIZATIONAL INFLUENCES}

\section{A. Resource Management}

\section{Human}

21. Passenger and freight pilots can find work flying in Alaska even if they have prior aviation accidents on their record.

\begin{tabular}{rrrrcc} 
& \multicolumn{5}{c}{ Descriptive Statistics } \\
& n & Mean & SD & \% Disagree & $\%$ Agree \\
Non-CFIT Company Pilots & 192 & 4.45 & 1.19 & 9.9 & 60.9 \\
CFIT Company Pilots & 63 & 4.65 & 1.08 & 7.9 & 68.3
\end{tabular}

59. In the last two years, I have received training on weather and weather avoidance approximately:

$$
\text { Non-CFIT Company Pilots }
$$$$
\text { CFIT Company Pilots }
$$

79. Rank the following methods according to how effective each is in obtaining qualified pilots for your company.

a. Conducting pre-employment background checks.

\begin{tabular}{rrrr} 
& \multicolumn{3}{c}{ Descriptive Statistics } \\
& n & Mean & SD \\
Non-CFIT Company Pilots & 206 & 2.61 & 1.36 \\
CFIT Company Pilots & 58 & 2.31 & 1.31
\end{tabular}

Note: Response options were reversed to maintain a consistent direction for scoring.

\section{Response Distribution (percent)}
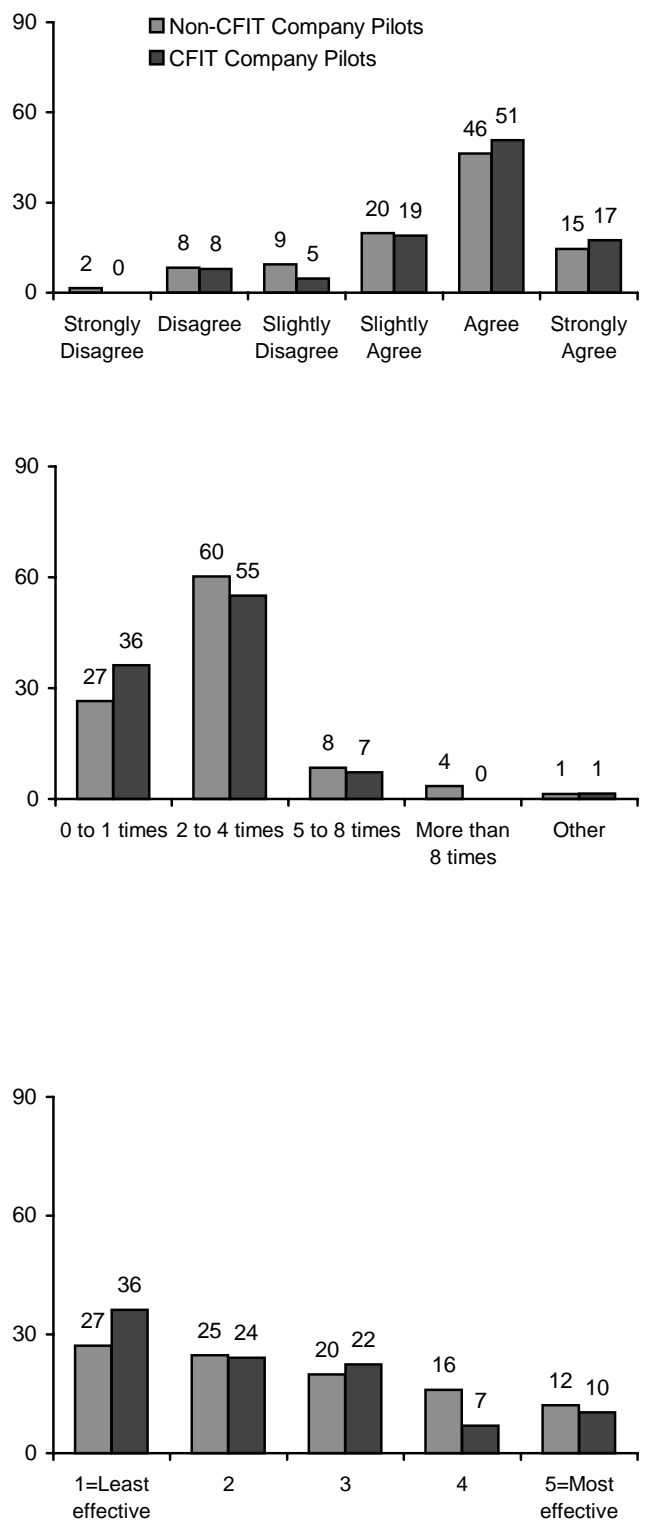

${ }^{1}$ significant difference (Chi square) $p<.05$

${ }^{2}$ significant difference (Mann-Whitney) $p<.05$

$\%$ Disagree=Strongly Disagree or Disagree

$\%$ Agree $=$ Strongly Agree or Agree 
b. Reviewing pilot's past accident records.

\begin{tabular}{rrrr} 
& \multicolumn{3}{c}{ Descriptive Statistics } \\
& n & Mean & SD \\
Non-CFIT Company Pilots & 203 & 2.16 & 1.05 \\
CFIT Company Pilots & 59 & 2.37 & 1.20
\end{tabular}

Note: Response options were reversed to maintain a consistent direction for scoring.

c. Conducting check rides.

$\begin{array}{rrrr} & & & \\ & \text { n } & \text { Mean } & \text { SD } \\ \text { Non-CFIT Company Pilots } & 201 & 3.21 & 1.36 \\ \text { CFIT Company Pilots } & 60 & 3.53 & 1.38\end{array}$

Note: Response options were reversed to maintain a consistent direction for scoring.

d. Conducting face-to-face interviews.

\begin{tabular}{rrrr} 
& \multicolumn{3}{c}{ Descriptive Statistics } \\
& n & Mean & SD \\
Non-CFIT Company Pilots & 205 & 3.67 & 1.23 \\
CFIT Company Pilots & 61 & 3.44 & 1.27
\end{tabular}

Note: Response options were reversed to maintain a consistent direction for scoring.

e. Getting recommendations from other pilots.

$\begin{array}{rrrr} & & & \\ & \text { n } & \text { Mean } & \text { SD } \\ \text { Non-CFIT Company Pilots } & 207 & 3.35 & 1.51 \\ \text { CFIT Company Pilots } & 61 & 3.36 & 1.41\end{array}$

Note: Response options were reversed to maintain a consistent direction for scoring.

\section{Response Distribution (percent)}
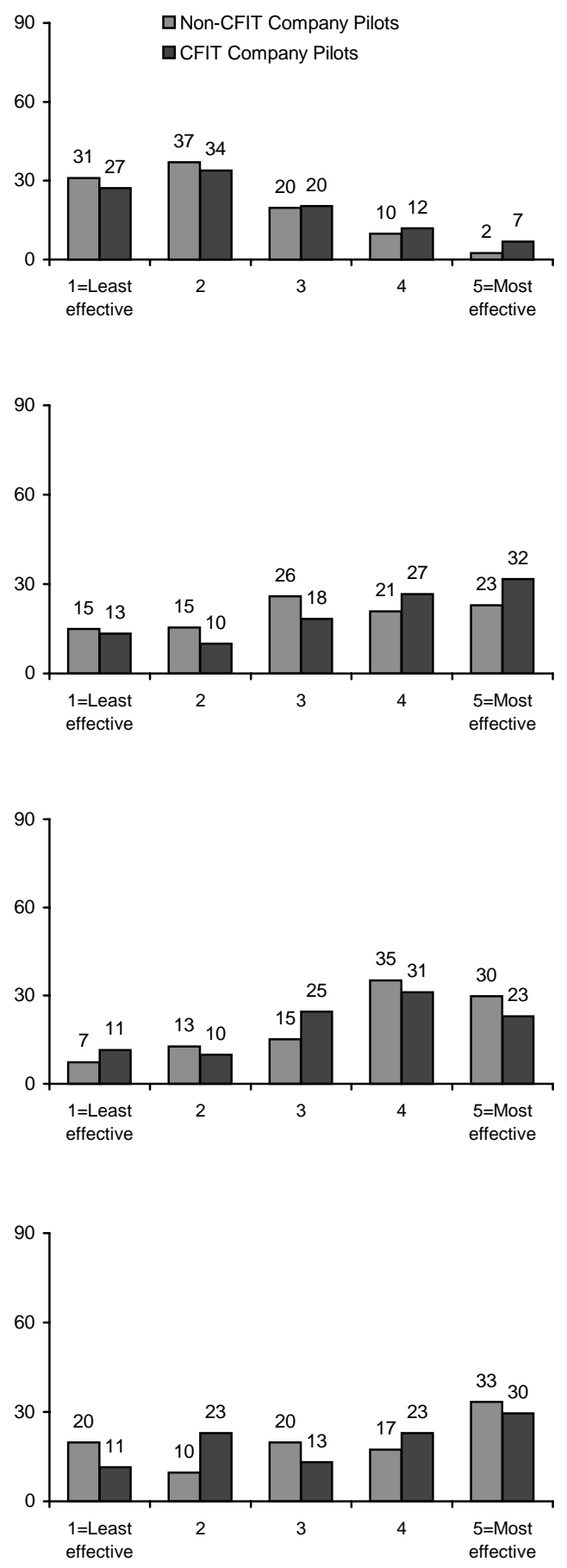

${ }^{1}$ significant difference (Chi square) $p<.05$

${ }^{2}$ significant difference (Mann-Whitney) $p<.05$

$\%$ Disagree=Strongly Disagree or Disagree

$\%$ Agree=Strongly Agree or Agree 


\section{Money}

60. My company provides sufficient maintenance on each of the following aircraft components (Choose all that apply) :

$\begin{array}{rrr}\begin{array}{r}\text { Non-CFIT } \\ \text { Company } \\ \text { Pilots } \\ (\mathrm{n}=234)\end{array} & \begin{array}{r}\text { Company } \\ \text { Pilots }\end{array} \\ \text { percent } & \begin{array}{r}(\mathrm{n}=71) \\ \text { percent }\end{array} & \text { sig. } \\ & & \\ 92.3 & 91.5 & \\ 86.3 & 69.0 & 1 \\ 78.6 & 64.8 & 1 \\ 86.3 & 66.2 & 1 \\ 91.0 & 91.5 & \\ 91.0 & 87.3 & \end{array}$

\section{Equipment}
a. Engine
b. Basic flight instruments
c. Navigation instruments
d. Communication equipment
e. Flight controls
f. Airframe

Response Distribution (percent)

61. The average age of the aircraft my company uses is years old.

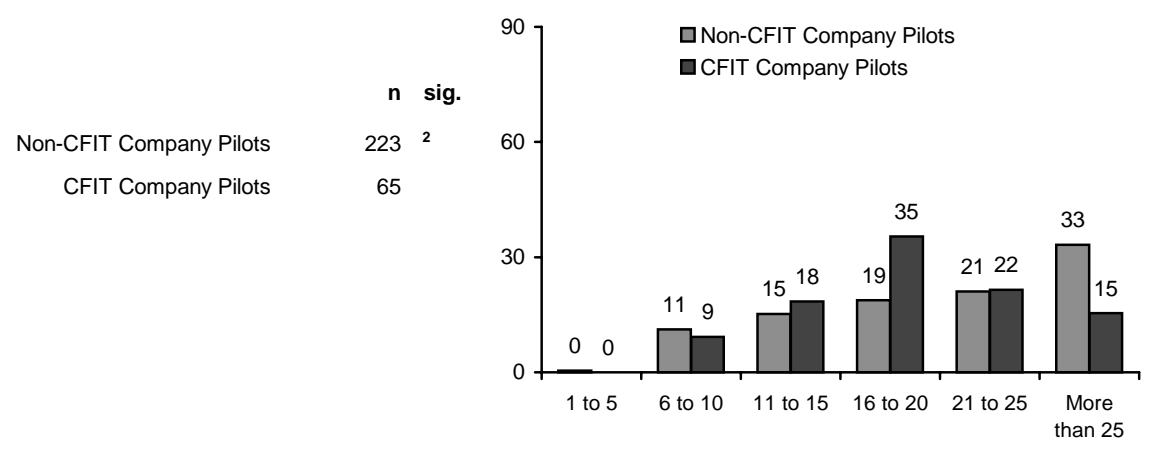

62. What kind of navigational equipment do you use when flying VMC through low visibility (choose all that apply)?

$\begin{array}{rr}\begin{array}{r}\text { Non-CFIT } \\ \text { Company } \\ \text { Pilots }\end{array} & \begin{array}{r}\text { CFIT } \\ \text { Company } \\ \text { Pilots }\end{array} \\ (\mathrm{n}=234) & (\mathrm{n}=71) \\ \text { percent } & \text { percent } \\ 70.9 & 78.9 \\ 3.0 & 1.4 \\ 17.1 & 15.5 \\ 12.0 & 16.9 \\ 32.9 & 33.8\end{array}$

${ }^{1}$ significant difference (Chi square) $p<.05$

${ }^{2}$ significant difference (Mann-Whitney) $p<.05$

$\%$ Disagree=Strongly Disagree or Disagree

$\%$ Agree=Strongly Agree or Agree
a. Global Positioning System unit
b. Head-up display
c. Ground Proximity Warning SysteI
d. Auto-pilot
e. Other 


\section{B. Organizational Climate}

22. In Alaska, if one passenger or freight company does not fly because of weather, there is a chance that the company next door will go ahead and fly.

\begin{tabular}{rrrrcc} 
& \multicolumn{5}{c}{ Descriptive Statistics } \\
& n & Mean & SD & \% Disagree & \% Agree \\
Non-CFIT Company Pilots & 225 & 4.69 & 1.14 & 7.6 & 68.0 \\
CFIT Company Pilots & 70 & 4.70 & 1.11 & 7.1 & 64.3
\end{tabular}

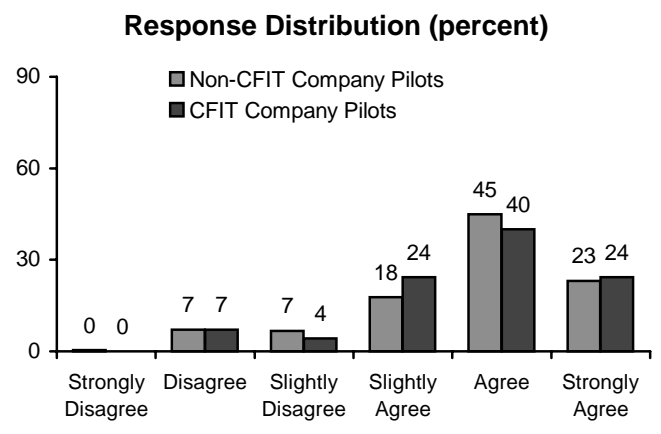

\section{Structure}

9. I am satisfied with the way my company deals with pilot complaints.

\begin{tabular}{rrrrcc} 
& \multicolumn{5}{c}{ Descriptive Statistics } \\
& n & Mean & SD & $\%$ Disagree & \% Agree \\
Non-CFIT Company Pilots & 219 & 4.03 & 1.76 & 26.0 & 58.9 \\
CFIT Company Pilots & 68 & 3.71 & 1.46 & 25.0 & 42.6
\end{tabular}

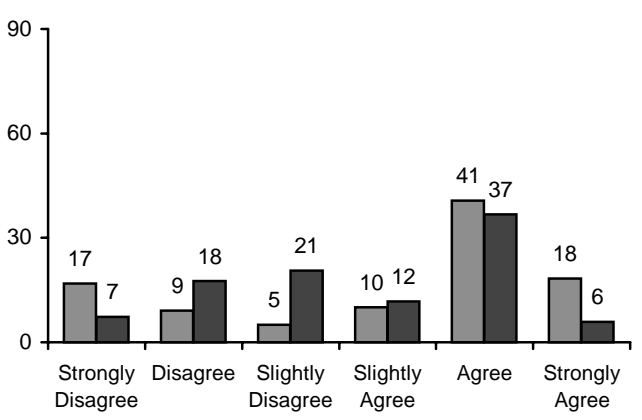

63. Who makes the final pre-departure go-no-go decision (choose all that apply)?

$\begin{array}{rrr}\begin{array}{r}\text { Non-CFIT } \\ \text { Company } \\ \text { Pilots }\end{array} & \begin{array}{r}\text { ComplT } \\ \text { Pilots }\end{array} \\ (\mathrm{n}=234) & \begin{array}{r}(\mathrm{n}=71) \\ \text { percent }\end{array} & \\ & \text { percent } & \text { sig. } \\ 27.4 & 26.8 & \\ 12.4 & 23.9 & 1 \\ 91.0 & 97.2 & \\ 4.3 & 2.8 & \end{array}$

${ }^{1}$ significant difference (Chi square) $p<.05$

${ }^{2}$ significant difference (Mann-Whitney) $p<.05$

$\%$ Disagree=Strongly Disagree or Disagree

$\%$ Agree=Strongly Agree or Agree
a. Director of Operations or Chief Pilot
b. Flight follower or dispatcher
c. Pilot
d. Other

2.8 
80. Rank the following according to who has the greatest responsibility for pre-departure weather evaluations.

a. Company management (i.e., Director of Operations or Chief Pilot)

$\begin{array}{rrrr} & & & \\ & \text { n } & \text { Mean } & \text { SD } \\ & & & \\ \text { Non-CFIT Company Pilots } & 210 & 2.59 & 0.69 \\ \text { CFIT Company Pilots } & 63 & 2.41 & 0.71\end{array}$

Note: Response options were reversed to maintain a consistent direction for scoring.

b. Flight follower or dispatcher

$\begin{array}{rrrr} & & & \\ & \text { n } & \text { Mean } & \text { SD } \\ \text { Non-CFIT Company Pilots } & 196 & 2.53 & 0.62 \\ \text { CFIT Company Pilots } & 58 & 2.69 & 0.63\end{array}$

Note: Response options were reversed to maintain a consistent direction for scoring.

c. Pilot

\begin{tabular}{rrrr} 
& \multicolumn{3}{c}{ Descriptive Statistics } \\
& n & Mean & SD \\
Non-CFIT Company Pilots & 223 & 3.84 & 0.44 \\
CFIT Company Pilots & 70 & 3.86 & 0.35
\end{tabular}

Note: Response options were reversed to maintain a consistent direction for scoring.

d. Other

\begin{tabular}{rrrr} 
& \multicolumn{3}{c}{ Descriptive Statistics } \\
& $\mathbf{n}$ & Mean & SD \\
Non-CFIT Company Pilots & 32 & 1.69 & 0.97 \\
CFIT Company Pilots & 10 & 1.70 & 0.95
\end{tabular}

Note: Response options were reversed to maintain a consistent direction for scoring.

${ }^{1}$ significant difference (Chi square) $p<.05$

${ }^{2}$ significant difference (Mann-Whitney) $p<.05$

$\%$ Disagree=Strongly Disagree or Disagree

$\%$ Agree=Strongly Agree or Agree

\section{Response Distribution (percent)}
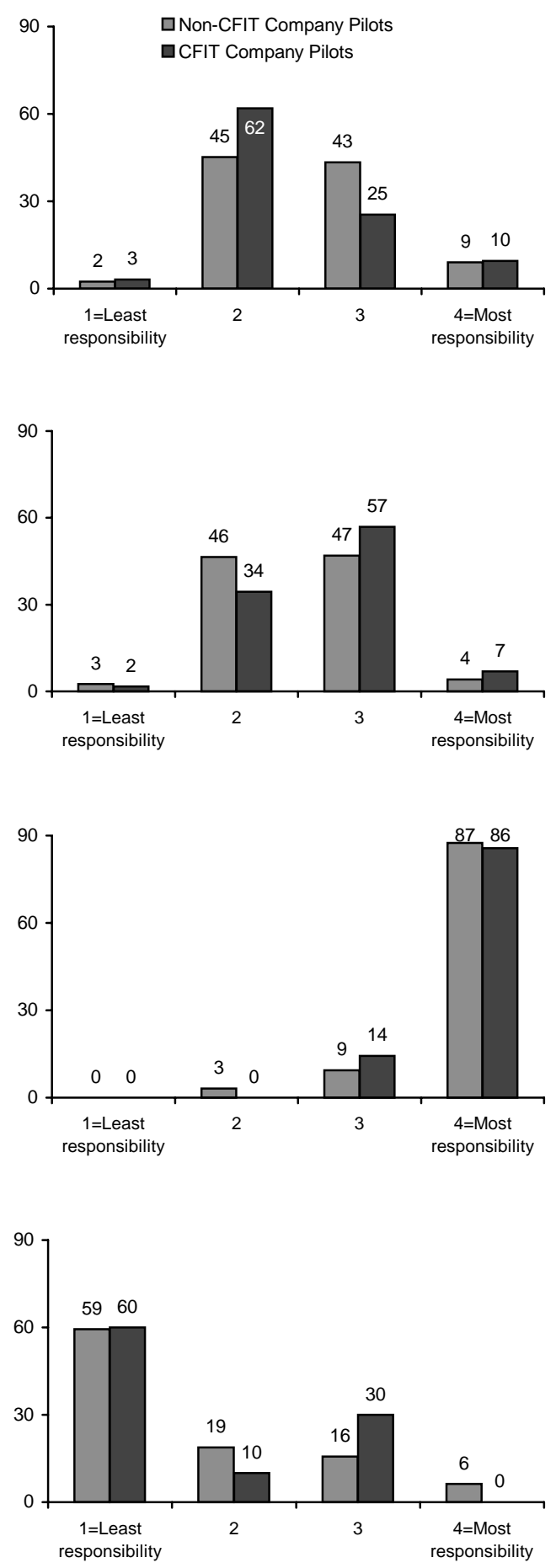


\section{$\underline{\text { Policies }}$}

17. My company considers the safety of its pilots as its top priority.

\begin{tabular}{rrrrrrl} 
& \multicolumn{7}{c}{ Descriptive Statistics } \\
& n & Mean & SD & \% Disagree & $\%$ Agree & sig. \\
Non-CFIT Company Pilots & 226 & 4.39 & 1.60 & 16.8 & 59.7 & 2 \\
CFIT Company Pilots & 69 & 4.04 & 1.44 & 17.4 & 46.4 &
\end{tabular}

23. In Alaska, passenger and freight companies rarely question a pilot's decision to turn around due to weather.

\begin{tabular}{rrrrcc} 
& \multicolumn{5}{c}{ Descriptive Statistics } \\
& n & Mean & SD & $\%$ Disagree & \% Agree \\
Non-CFIT Company Pilots & 226 & 3.64 & 1.42 & 24.8 & 37.2 \\
CFIT Company Pilots & 68 & 3.81 & 1.34 & 19.1 & 35.3
\end{tabular}

24. Passenger and freight pilots in Alaska are encouraged to turn around when the weather deteriorates en route.

\begin{tabular}{rrrrcc} 
& \multicolumn{5}{c}{ Descriptive Statistics } \\
& n & Mean & SD & $\%$ Disagree & $\%$ Agree \\
Non-CFIT Company Pilots & 226 & 4.12 & 1.25 & 12.8 & 46.0 \\
CFIT Company Pilots & 70 & 4.31 & 0.97 & 5.7 & 50.0
\end{tabular}

\section{$\underline{\text { Culture }}$}

10. My company stays in touch with pilot concerns and problems.

\begin{tabular}{rrrrcc} 
& \multicolumn{5}{c}{ Descriptive Statistics } \\
& n & Mean & SD & \% Disagree & \% Agree \\
Non-CFIT Company Pilots & 225 & 4.11 & 1.68 & 24.4 & 57.3 \\
CFIT Company Pilots & 69 & 3.84 & 1.48 & 23.2 & 40.6
\end{tabular}

${ }^{1}$ significant difference (Chi square) $p<.05$

${ }^{2}$ significant difference (Mann-Whitney) $\mathrm{p}<.05$

$\%$ Disagree=Strongly Disagree or Disagree

$\%$ Agree=Strongly Agree or Agree

\section{Response Distribution (percent)}
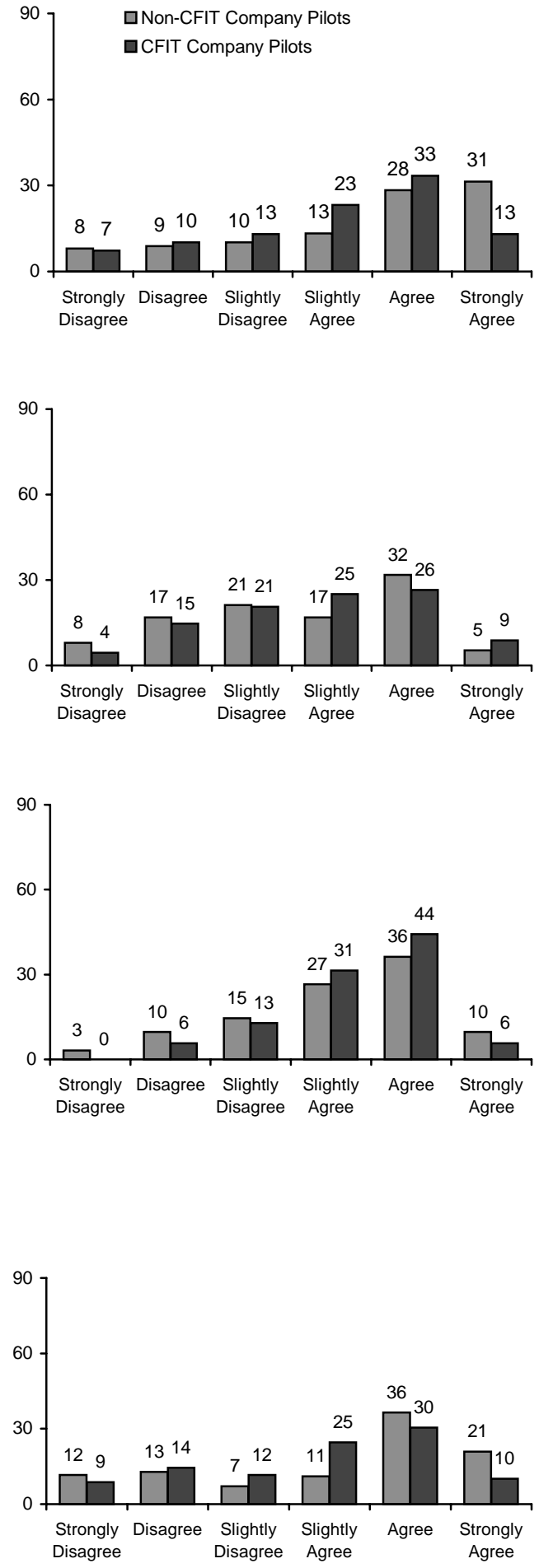
11. In my company pilot morale is high.

\begin{tabular}{rrrrrrrl} 
& \multicolumn{7}{c}{ Descriptive Statistics } \\
& n & Mean & SD & \% Disagree & \% Agree & sig. \\
Non-CFIT Company Pilots & 229 & 3.94 & 1.73 & 24.9 & 49.8 & 2 \\
CFIT Company Pilots & 69 & 3.30 & 1.57 & 37.7 & 31.9 &
\end{tabular}

12. My company appreciates the good work that I do.

\begin{tabular}{rrrrcc} 
& \multicolumn{5}{c}{ Descriptive Statistics } \\
& n & Mean & SD & \% Disagree & \% Agree \\
Non-CFIT Company Pilots & 222 & 4.29 & 1.56 & 18.0 & 58.1 \\
CFIT Company Pilots & 69 & 4.10 & 1.29 & 14.5 & 46.4
\end{tabular}

13. In my company getting the job done has higher priority than safety.

\begin{tabular}{rrrrcc} 
& \multicolumn{5}{c}{ Descriptive Statistics } \\
& n & Mean & SD & \% Disagree & \% Agree \\
Non-CFIT Company Pilots & 229 & 2.40 & 1.60 & 68.6 & 15.3 \\
CFIT Company Pilots & 69 & 2.80 & 1.48 & 44.9 & 11.6
\end{tabular}

14. My company is more concerned about making money than being safe.

\begin{tabular}{rrrrcc} 
& \multicolumn{5}{c}{ Descriptive Statistics } \\
& n & Mean & SD & \% Disagree & \% Agree \\
Non-CFIT Company Pilots & 228 & 2.33 & 1.61 & 71.1 & 15.4 \\
CFIT Company Pilots & 69 & 2.51 & 1.38 & 56.5 & 13.0
\end{tabular}

\section{Response Distribution (percent)}
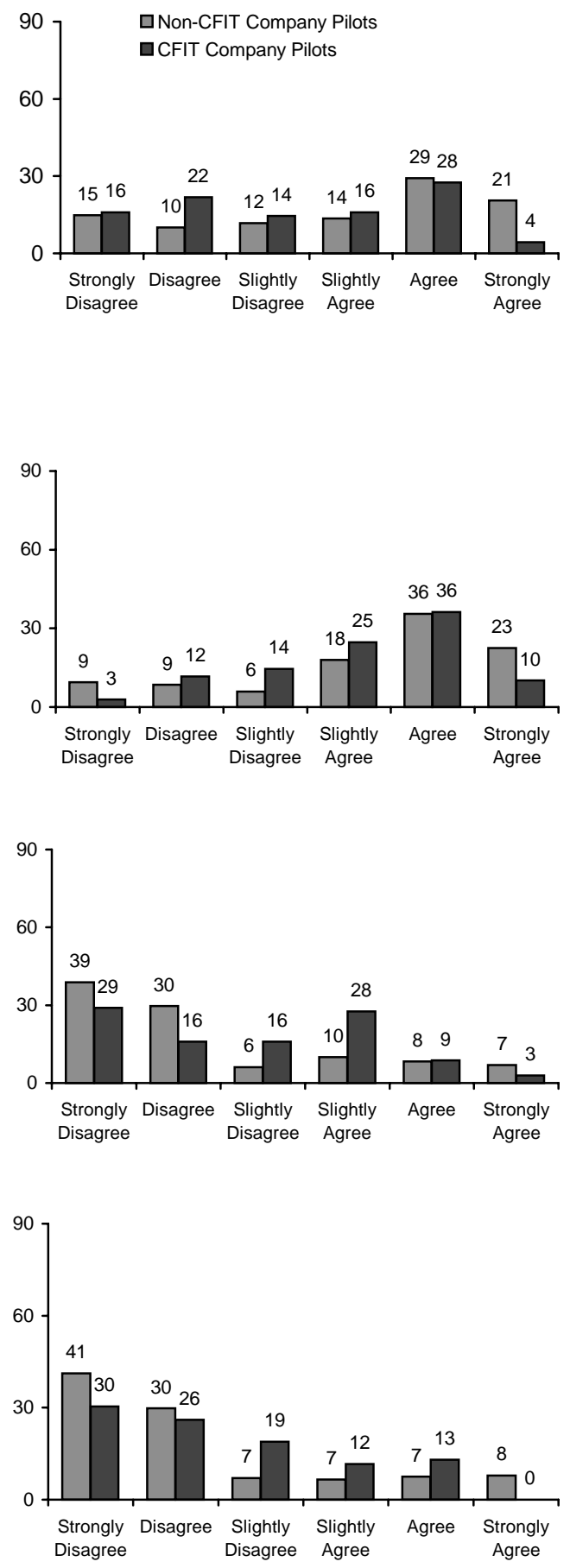

\footnotetext{
${ }^{1}$ significant difference (Chi square) $p<.05$

${ }^{2}$ significant difference (Mann-Whitney) $p<.05$

$\%$ Disagree=Strongly Disagree or Disagree

$\%$ Agree=Strongly Agree or Agree
} 
15. My company does all that it can to prevent accidents.

\begin{tabular}{rrrcccc} 
& \multicolumn{8}{c}{ Descriptive Statistics } \\
& n & Mean & SD & \% Disagree & \% Agree & sig. \\
Non-CFIT Company Pilots & 227 & 4.60 & 1.51 & 14.1 & 66.5 & 2 \\
CFIT Company Pilots & 69 & 4.17 & 1.40 & 15.9 & 50.7 &
\end{tabular}

16. My company does not cut corners where safety is concerned.

\begin{tabular}{rrrcccc} 
& & \multicolumn{8}{c}{ Descriptive Statistics } \\
& n & Mean & SD & \% Disagree & \% Agree & sig. \\
Non-CFIT Company Pilots & 227 & 4.56 & 1.45 & 14.1 & 64.8 & 2 \\
CFIT Company Pilots & 69 & 3.99 & 1.38 & 14.5 & 43.5 &
\end{tabular}

\section{Organizational Process}

\section{Operations}

25. Passenger and freight companies in Alaska operate on small profit margins.

\begin{tabular}{rrrccc} 
& \multicolumn{7}{c}{ Descriptive Statistics } \\
& n & Mean & SD & \% Disagree & \% Agree \\
Non-CFIT Company Pilots & 210 & 4.65 & 1.32 & 10.5 & 66.2 \\
CFIT Company Pilots & 67 & 4.78 & 1.25 & 9.0 & 74.6
\end{tabular}

26. In my company, safety awards are used to promote safe flying.

\begin{tabular}{rrrcccc} 
& \multicolumn{8}{c}{ Descriptive Statistics } \\
& n & Mean & SD & \% Disagree & \% Agree & sig \\
Non-CFIT Company Pilots & 165 & 2.78 & 1.60 & 63.6 & 23.0 & 2 \\
CFIT Company Pilots & 58 & 2.21 & 1.32 & 79.3 & 12.1 &
\end{tabular}

\footnotetext{
${ }^{1}$ significant difference (Chi square) $p<.05$

${ }^{2}$ significant difference (Mann-Whitney) $p<.05$

$\%$ Disagree=Strongly Disagree or Disagree

$\%$ Agree=Strongly Agree or Agree
}

\section{Response Distribution (percent)}

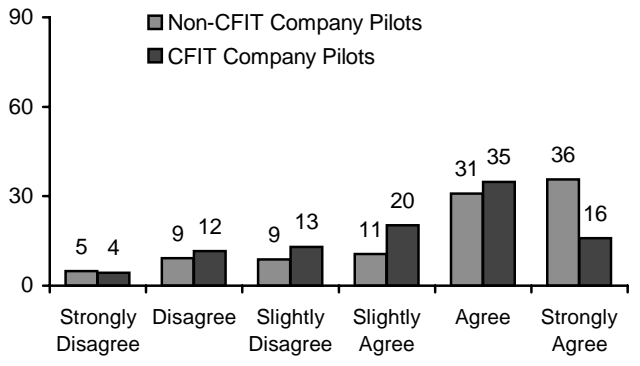

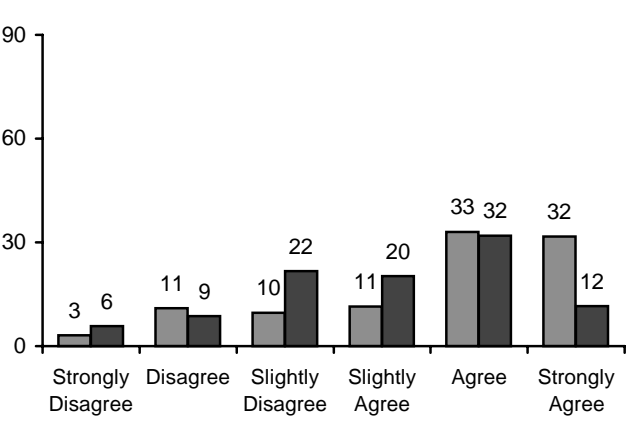
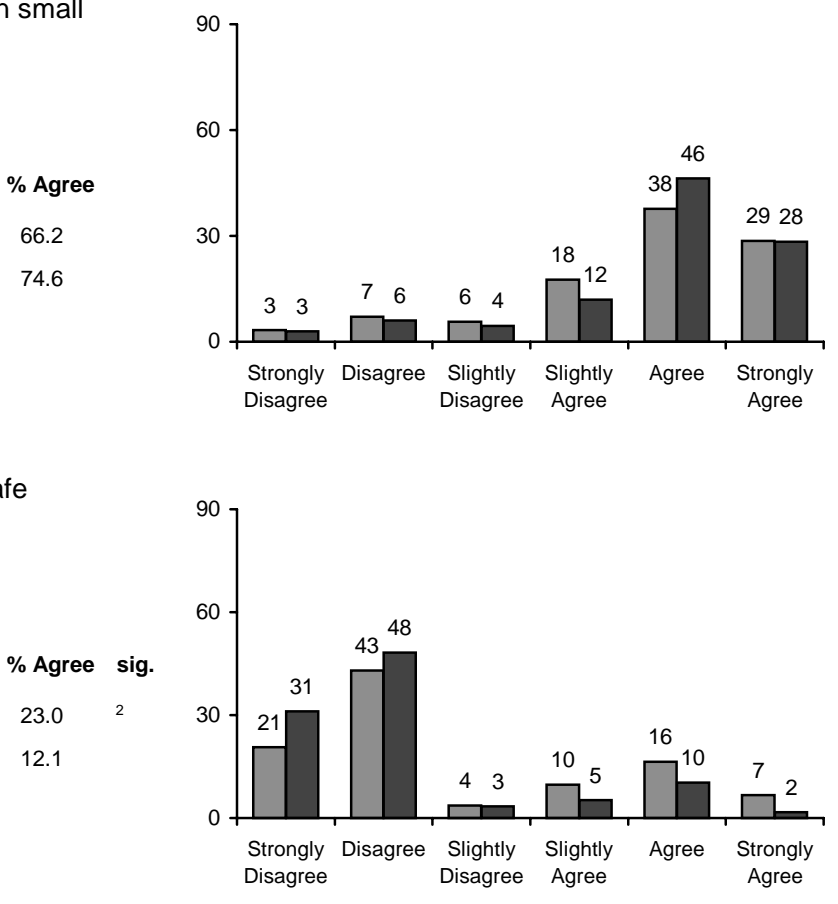
64. Indicate the method used to determine your pay.

Response Distribution (percent)

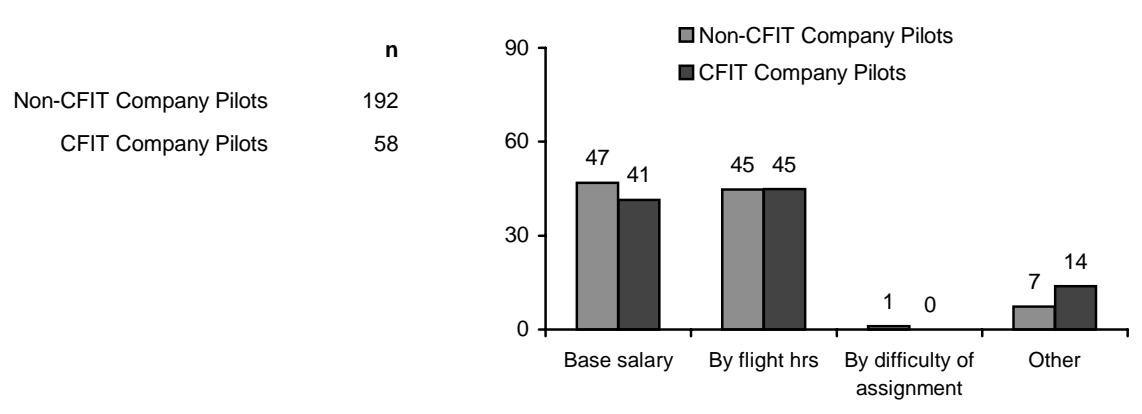

65. The majority of my flights are flown over the following terrain (choose all that apply):

a terrain
a Flat terrain
b Open water
c Channels, islands and peninsule
d Hills
e Hills and mountains
f. Mountains and mountain passes
g Other

$\begin{array}{rr}\begin{array}{r}\text { Non-CFIT } \\ \text { Company } \\ \text { Pilots }\end{array} & \begin{array}{r}\text { CFIT } \\ \text { Company } \\ \text { Pilots } \\ (\mathrm{n}=234)\end{array} \\ \text { percent } & \text { percent } \\ & \\ 63.7 & 62.0 \\ 47.0 & 40.8 \\ 39.7 & 43.7 \\ 38.9 & 42.3 \\ 68.4 & 71.8 \\ 59.8 & 52.1 \\ 8.1 & 5.6\end{array}$

66. My company's safety practices are (select one):

$\begin{array}{rrrrrl} & & & & \\ & \text { n } & \text { Mean } & \text { SD } & \text { sig. } \\ \text { Non-CFIT Company Pilots } & 231 & 3.67 & 1.04 & 2 \\ \text { CFIT Company Pilots } & 70 & 3.19 & 0.97\end{array}$

Note: Response options were reversed to maintain a consistent direction for scoring.

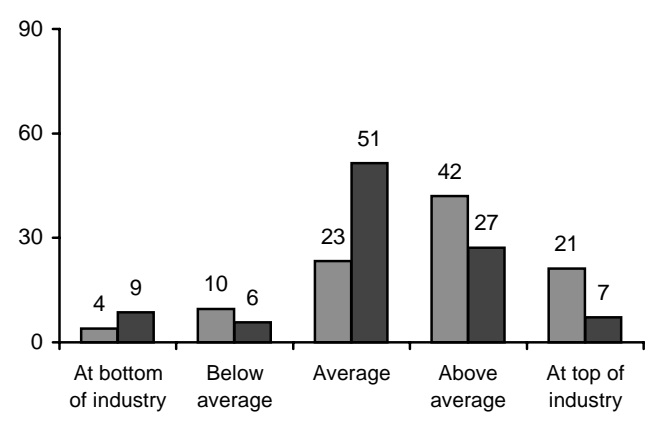

\section{Procedures}

27. Alaskan passenger and freight companies formally teach unwritten "rules of thumb" for flying in areas of low ceiling and reduced visibility.

\begin{tabular}{rrrccc} 
& \multicolumn{5}{c}{ Descriptive Statistics } \\
& n & Mean & SD & \% Disagree & \% Agree \\
Non-CFIT Company Pilots & 220 & 3.80 & 1.47 & 26.4 & 40.5 \\
CFIT Company Pilots & 67 & 4.07 & 1.47 & 23.9 & 50.7
\end{tabular}

${ }^{1}$ significant difference (Chi square) $p<.05$

${ }^{2}$ significant difference (Mann-Whitney) $p<.05$

$\%$ Disagree=Strongly Disagree or Disagree

$\%$ Agree=Strongly Agree or Agree

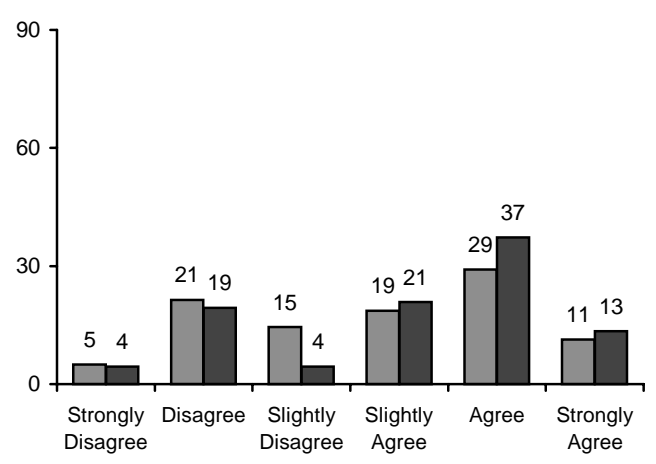


28. Pilot training on how to operate in low visibility conditions is provided by my company.

\section{Descriptive Statistics}

$\begin{array}{rrrccc} & \text { n } & \text { Mean } & \text { SD } & \text { \% Disagree } & \text { \% Agree } \\ \text { Non-CFIT Company Pilots } & 222 & 3.71 & 1.59 & 36.0 & 45.9 \\ \text { CFIT Company Pilots } & 61 & 3.66 & 1.58 & 32.8 & 45.9\end{array}$

29. My company launches weather reporting observation flights to supplement pre-departure weather services.

\begin{tabular}{rrrccc} 
& \multicolumn{5}{c}{ Descriptive Statistics } \\
& n & Mean & SD & \% Disagree & \% Agree \\
Non-CFIT Company Pilots & 186 & 2.75 & 1.63 & 64.0 & 26.3 \\
CFIT Company Pilots & 57 & 2.93 & 1.66 & 59.6 & 26.3
\end{tabular}

67. My company uses each of the following weather reporting services during pre-departure weather evaluations (choose all that apply):
a. National Weather Service
b. Flight Service Station
c. Automated Flight Service Station
d. Station Agents
e. Pilot Observations
f. Other

83. My company's training program contains an inadvertent IMC recovery procedure.

Non-CFIT Company Pilots

\section{Response Distribution (percent)}
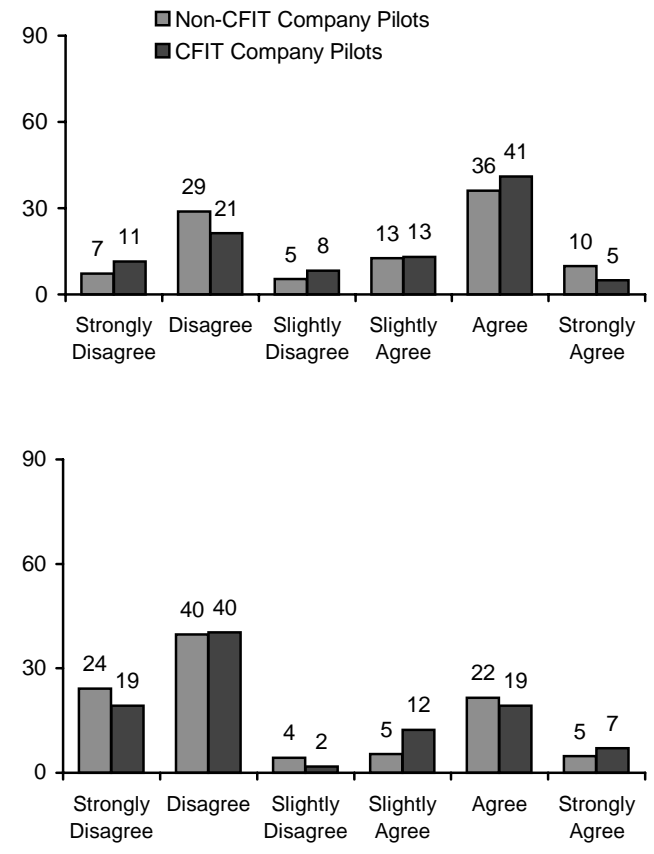

$\begin{array}{rrr}\begin{array}{r}\text { Non-CFIT } \\ \text { Company } \\ \text { Pilots }\end{array} & \begin{array}{r}\text { CFIT } \\ \text { Company } \\ \text { Pilots }\end{array} \\ (\mathrm{n}=234) & \begin{array}{r}(\mathrm{n}=71) \\ \text { percent }\end{array} & \text { sig } \\ \text { percent } & 67.6 & \\ 67.5 & 87.3 & \\ 81.2 & 60.6 & \\ 59.4 & 60.6 & 1 \\ 46.2 & 74.6 & \\ 75.2 & 14.1 & \end{array}$

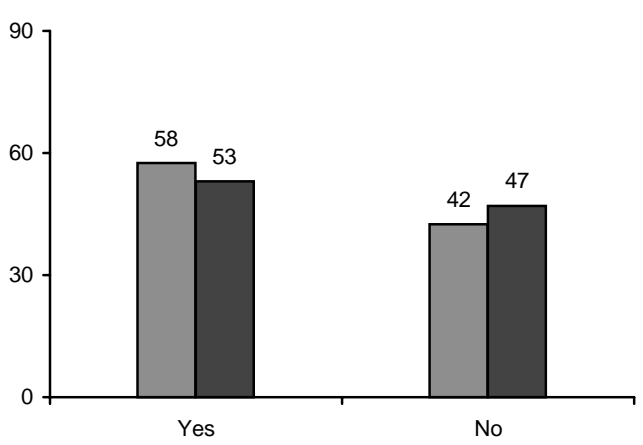

${ }^{1}$ significant difference (Chi square) $p<.05$

${ }^{2}$ significant difference (Mann-Whitney) $p<.05$

$\%$ Disagree=Strongly Disagree or Disagree

$\%$ Agree=Strongly Agree or Agree 
84. My company requires "re-dispatch" or "re-contact" with the company when pilots reroute due to weather.

Non-CFIT Company Pilots

CFIT Company Pilots

\section{Response Distribution (percent)}

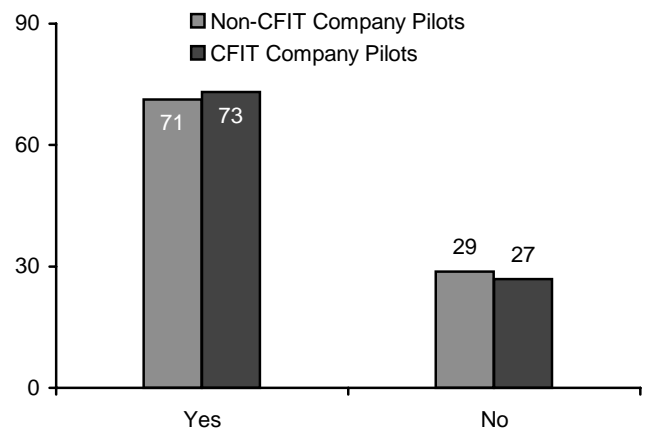

\section{Oversight}

30. My company conducts formal pilot safety meetings.

\begin{tabular}{rrrcccc} 
& \multicolumn{5}{c}{ Descriptive Statistics } \\
& n & Mean & SD & $\%$ Disagree & $\%$ Agree \\
Non-CFIT Company Pilots & 217 & 3.83 & 1.67 & 31.3 & 50.2 \\
CFIT Company Pilots & 66 & 3.47 & 1.60 & 34.8 & 36.4
\end{tabular}

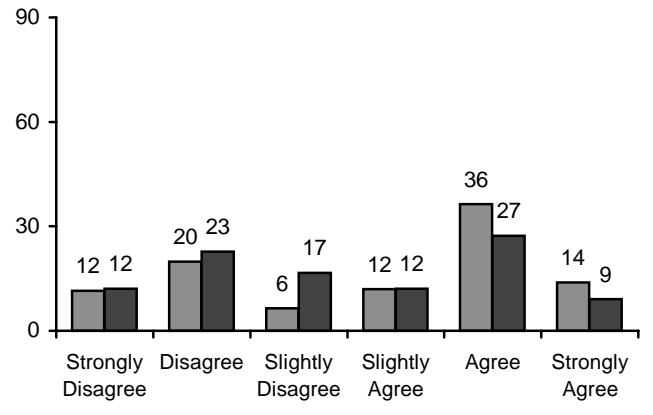

31. My company provides me with opportunities to make safety recommendations.

\begin{tabular}{rrrccccc} 
& \multicolumn{8}{c}{ Descriptive Statistics } \\
& n & Mean & SD & $\%$ Disagree & \% Agree & sig. \\
Non-CFIT Company Pilots & 224 & 4.72 & 1.27 & 8.5 & 73.2 & 2 \\
CFIT Company Pilots & 69 & 4.19 & 1.37 & 18.8 & 56.5 &
\end{tabular}

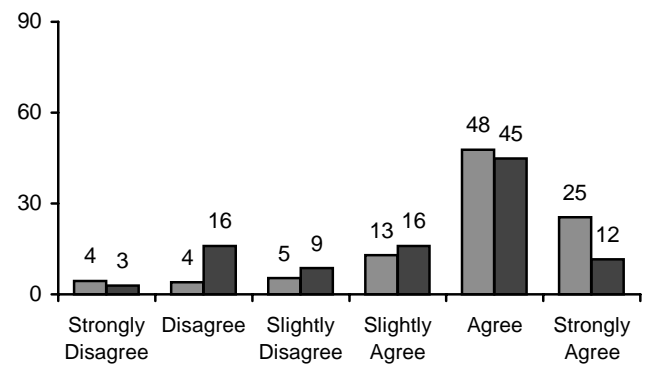

32. My company's safety meetings focus on hard-hitting safety issues that pilots face each day.

\begin{tabular}{rrrccc} 
& \multicolumn{5}{c}{ Descriptive Statistics } \\
& n & Mean & SD & \% Disagree & \% Agree \\
Non-CFIT Company Pilots & 199 & 3.91 & 1.61 & 27.6 & 46.7 \\
CFIT Company Pilots & 59 & 3.56 & 1.49 & 32.2 & 33.9
\end{tabular}

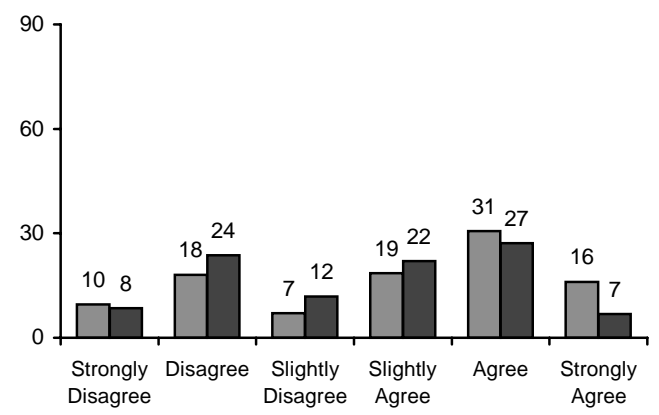

${ }^{1}$ significant difference (Chi square) $p<.05$

${ }^{2}$ significant difference (Mann-Whitney) $\mathrm{p}<.05$

$\%$ Disagree=Strongly Disagree or Disagree

$\%$ Agree=Strongly Agree or Agree 
85. My company's safety program includes something like a safety risk reporting form.

Non-CFIT Company Pilots

\section{Response Distribution (percent)}

n

217

68

86. My company's safety program includes something like a risk management or internal audit process?

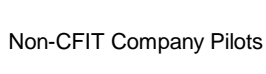

CFIT Company Pilots

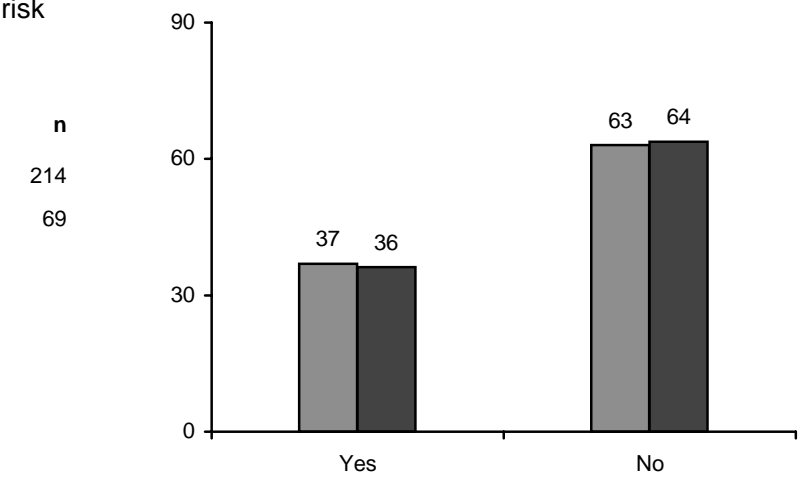

\section{UNSAFE SUPERVISION}

\section{A. Unforeseen}

\section{Unrecognized Hazardous Operations}

33. Before each flight, my company makes sure that pilots have the right frame of mind for flying.

\begin{tabular}{rrrcccc} 
& \multicolumn{8}{c}{ Descriptive Statistics } & & \\
& n & Mean & SD & \% Disagree & \% Agree & sig \\
Non-CFIT Company Pilots & 219 & 3.16 & 1.57 & 43.4 & 26.5 & 2 \\
CFIT Company Pilots & 67 & 2.70 & 1.37 & 53.7 & 13.4 &
\end{tabular}

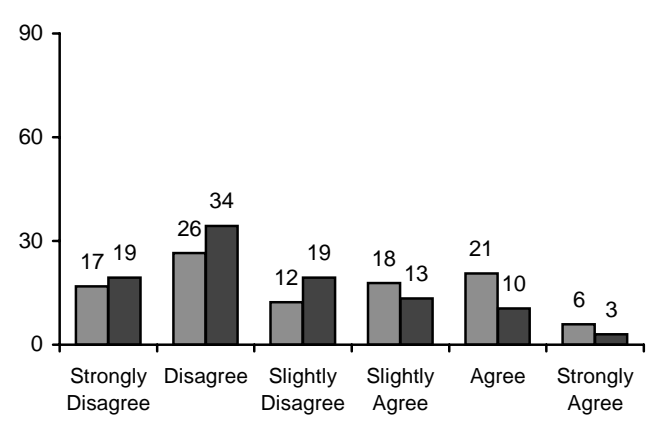

${ }^{1}$ significant difference (Chi square) $\mathrm{p}<.05$

${ }^{2}$ significant difference (Mann-Whitney) $p<.05$

$\%$ Disagree=Strongly Disagree or Disagree

$\%$ Agree $=$ Strongly Agree or Agree 
34. Before each flight, my company makes sure pilots are physically fit to fly (e.g., free from the adverse effects of fatigue, medications).

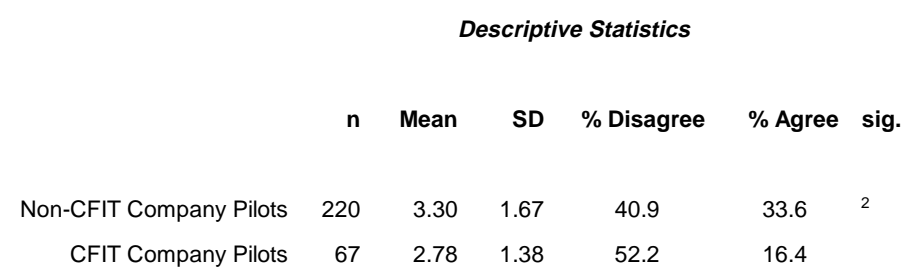

\section{Inadequate Documentation Procedures}

35. My company's Standard Operating Procedures manual is up to date.

\begin{tabular}{|c|c|c|c|c|c|}
\hline & \multicolumn{5}{|c|}{ Descriptive Statistics } \\
\hline & $\mathbf{n}$ & Mean & SD & $\%$ Disagree & $\%$ Agree \\
\hline Non-CFIT Company Pilots & 220 & 4.95 & 1.15 & 5.9 & 85.5 \\
\hline CFIT Company Pilots & 70 & 4.91 & 1.10 & 5.7 & 78.6 \\
\hline
\end{tabular}

\section{B. Known}

\section{Inadequate Supervision}

36. My company ensures that pilots obtain sufficient training on new equipment.

\begin{tabular}{rrrrcc} 
& \multicolumn{5}{c}{ Descriptive Statistics } \\
& n & Mean & SD & \% Disagree & \% Agree \\
Non-CFIT Company Pilots & 223 & 4.75 & 1.25 & 8.1 & 74.9 \\
CFIT Company Pilots & 69 & 4.59 & 1.13 & 5.8 & 63.8
\end{tabular}

\footnotetext{
${ }^{1}$ significant difference (Chi square) $p<.05$

${ }^{2}$ significant difference (Mann-Whitney) $\mathrm{p}<.05$

$\%$ Disagree=Strongly Disagree or Disagree

$\%$ Agree $=$ Strongly Agree or Agree
}

\section{Response Distribution (percent)}
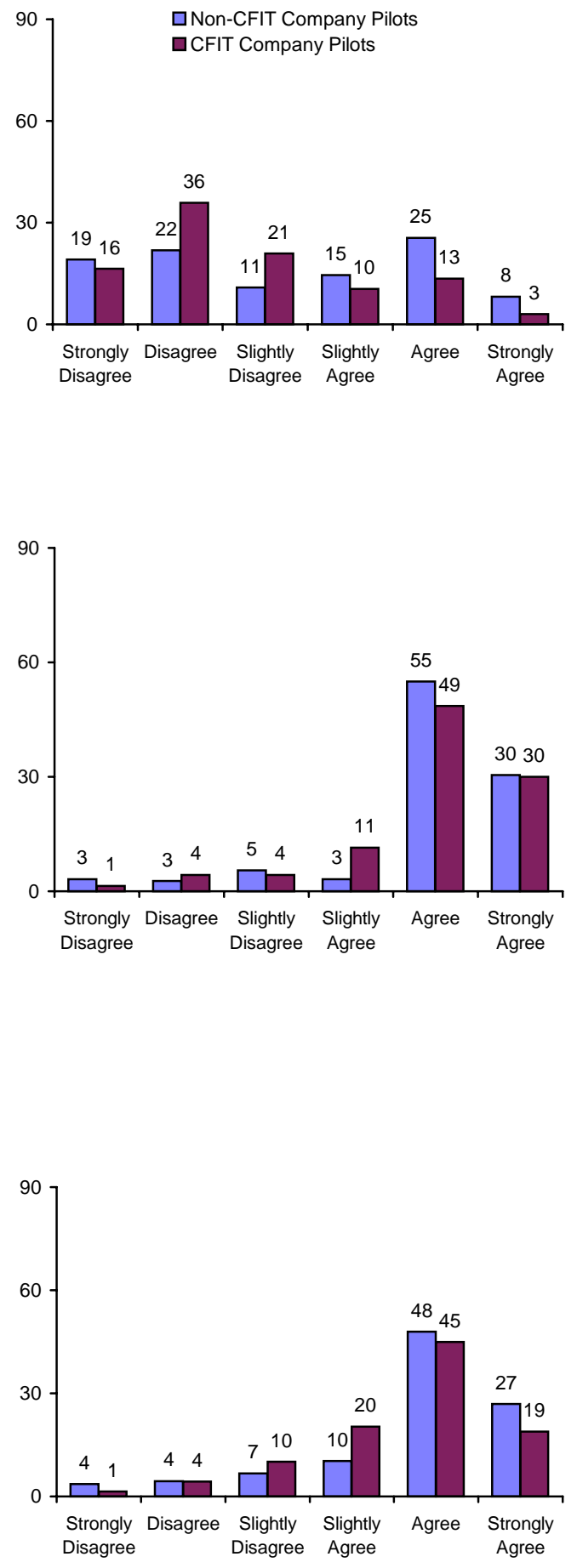


\section{$\underline{\text { Planned Inappropriate Operations }}$}

37. In Alaska, passenger and freight assignments require flying under marginal VMC.

\section{Response Distribution (percent)}

Descriptive Statistics

$\begin{array}{rrrrcc} & \mathbf{n} & \text { Mean } & \text { SD } & \text { \% Disagree } & \text { \% Agree } \\ \text { Non-CFIT Company Pilots } & 224 & 4.76 & 1.24 & 9.8 & 73.2 \\ \text { CFIT Company Pilots } & 69 & 5.03 & 1.06 & 5.8 & 81.2\end{array}$

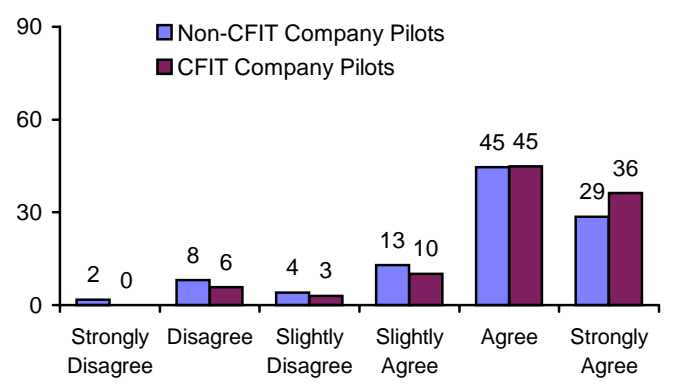

\section{Failed to Correct Problem}

68. The first time my company discovered I flew through weather below legal VFR, they would: (select one)

Non-CFIT Company Pilots

CFIT Company Pilots
90

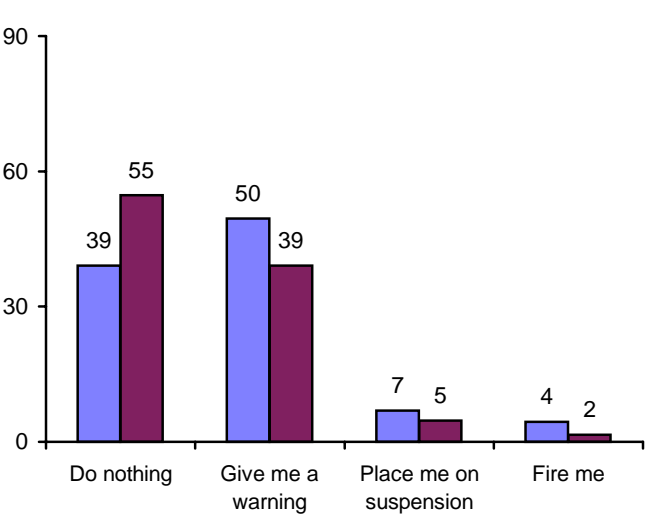

\section{PRECONDITIONS FOR UNSAFE ACTS}

18. As a pilot I am concerned about having an accident while flying.

\begin{tabular}{rrrrcc} 
& \multicolumn{5}{c}{ Descriptive Statistics } \\
& n & Mean & SD & \% Disagree & $\%$ Agree \\
Non-CFIT Company Pilots & 230 & 4.72 & 1.46 & 14.8 & 71.3 \\
CFIT Company Pilots & 70 & 4.53 & 1.64 & 20.0 & 64.3
\end{tabular}

\footnotetext{
${ }^{1}$ significant difference (Chi square) $\mathrm{p}<.05$

${ }^{2}$ significant difference (Mann-Whitney) $p<.05$

$\%$ Disagree=Strongly Disagree or Disagree

$\%$ Agree $=$ Strongly Agree or Agree
}

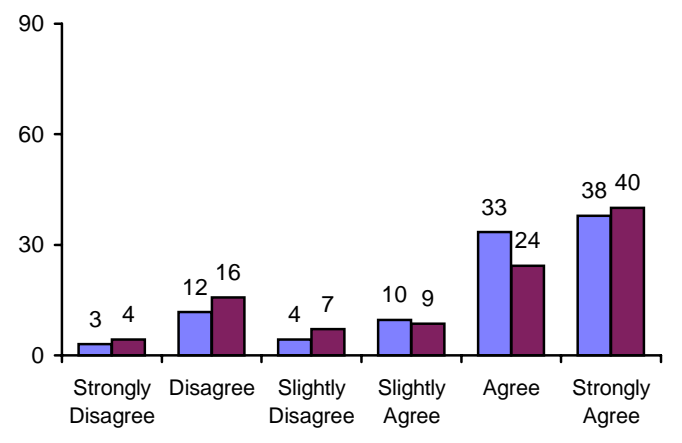




\section{A. Substandard Conditions}

38. In Alaska, safety would improve if the visibility requirement for special VFR (conducted under FAR Part 135) was increased to 2 miles when operating under a ceiling of less than 1000 feet.

\begin{tabular}{rrrcccc} 
& \multicolumn{8}{c}{ Descriptive Statistics } \\
& n & Mean & SD & \% Disagree & \% Agree & sig \\
Non-CFIT Company Pilots & 205 & 3.13 & 1.84 & 51.7 & 31.7 & 2 \\
CFIT Company Pilots & 68 & 3.65 & 1.79 & 39.7 & 47.1 &
\end{tabular}

39. In Alaska, passenger and freight pilots would feel comfortable flying VMC in low visibility over flat terrain or water.

\begin{tabular}{rrrrccc} 
& \multicolumn{6}{c}{ Descriptive Statistics } \\
& n & Mean & SD & \% Disagree & \% Agree \\
Non-CFIT Company Pilots & 215 & 3.77 & 1.50 & 27.4 & 41.4 \\
CFIT Company Pilots & 68 & 3.88 & 1.25 & 17.6 & 36.8
\end{tabular}

40. Alaskan passenger and freight pilots talk about having to "push" the weather during their flights.

$\begin{array}{rrrrrr} & & & & & \\ & n & \text { Mean } & \text { SD } & \text { \% Disagree } & \text { \% Agree } \\ \text { Non-CFIT Company Pilots } & 226 & 4.28 & 1.28 & 14.2 & 52.7 \\ \text { CFIT Company Pilots } & 70 & 4.49 & 1.19 & 10.0 & 58.6\end{array}$

41. In Alaska, one seldom sees passenger and freight pilots "push" the weather at community airports.

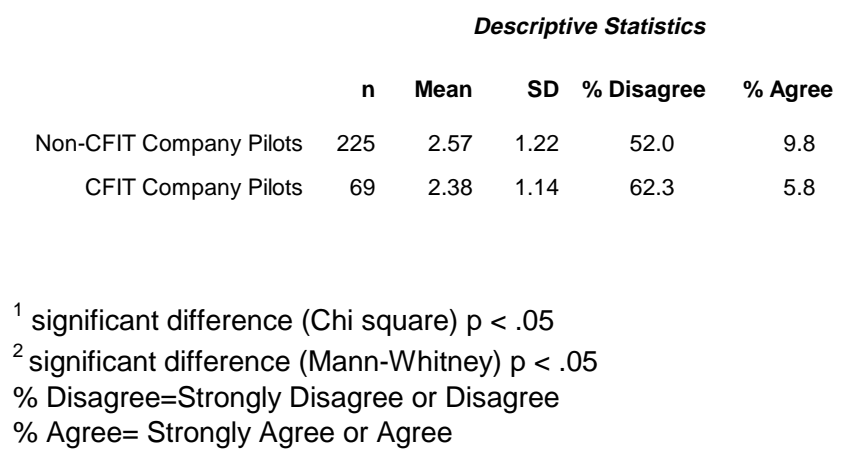

${ }^{1}$ significant difference (Chi square) $p<.05$

${ }^{2}$ significant difference (Mann-Whitney) $\mathrm{p}<.05$

$\%$ Disagree=Strongly Disagree or Disagree

$\%$ Agree= Strongly Agree or Agree

\section{Response Distribution (percent)}
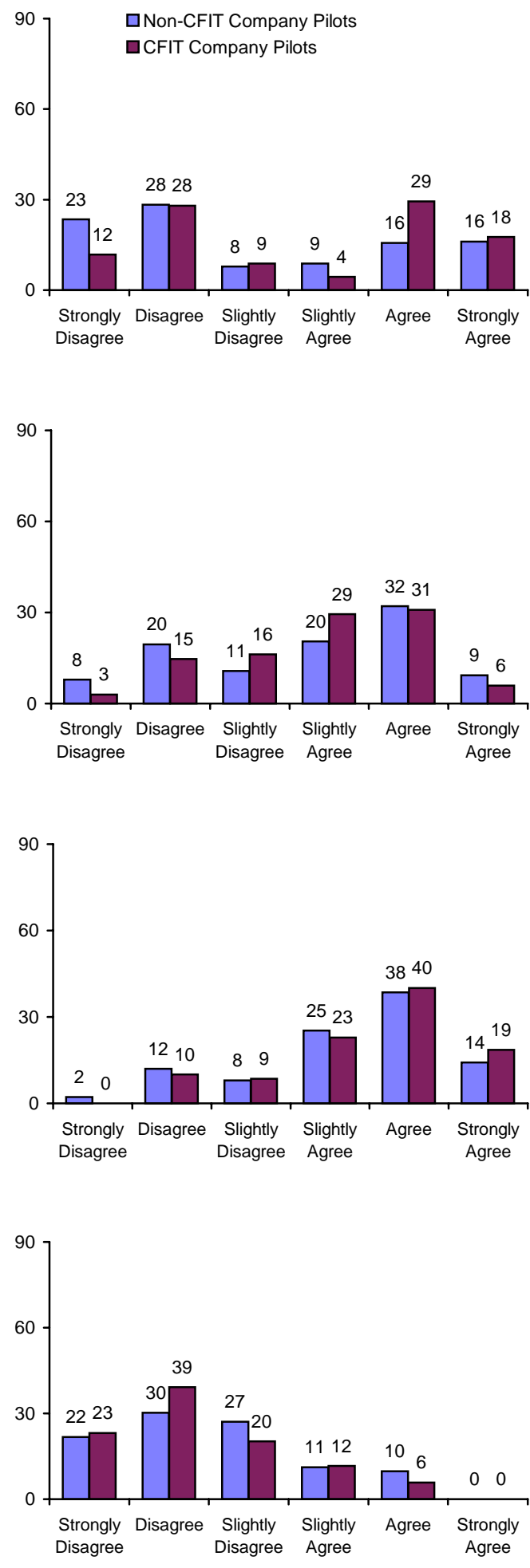
42. Passenger and freight pilots in Alaska would feel comfortable flying VMC in low visibility over hills and mountains.

\section{Descriptive Statistics}

$\begin{array}{rrrccc} & \mathbf{n} & \text { Mean } & \text { SD } & \text { \% Disagree } & \text { \% Agree } \\ \text { Non-CFIT Company Pilots } & 226 & 2.23 & 1.14 & 72.6 & 6.6 \\ \text { CFIT Company Pilots } & 68 & 2.32 & 1.09 & 67.6 & 5.9\end{array}$

\section{Response Distribution (percent)}

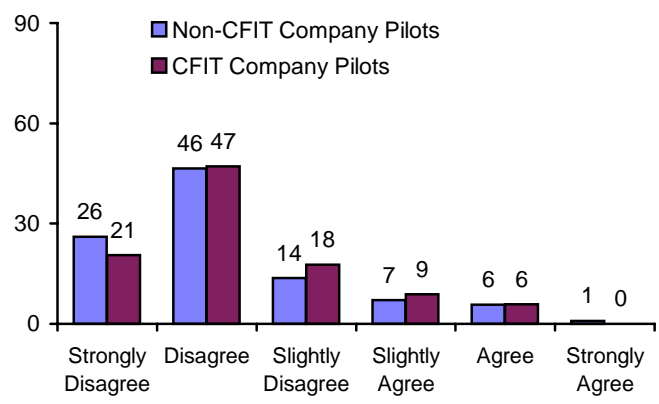

\section{Adverse Mental States}

43. In Alaska, during periods of extended daylight, pilot and copilot aircrews fly over 10 hours per day.

\begin{tabular}{rrrrcccc} 
& \multicolumn{8}{c}{ Descriptive Statistics } \\
& n & Mean & SD & $\%$ Disagree & \% Agree & sig. \\
Non-CFIT Company Pilots & 206 & 3.37 & 1.69 & 46.6 & 34.5 & 2 \\
CFIT Company Pilots & 65 & 2.66 & 1.41 & 66.2 & 16.9 &
\end{tabular}

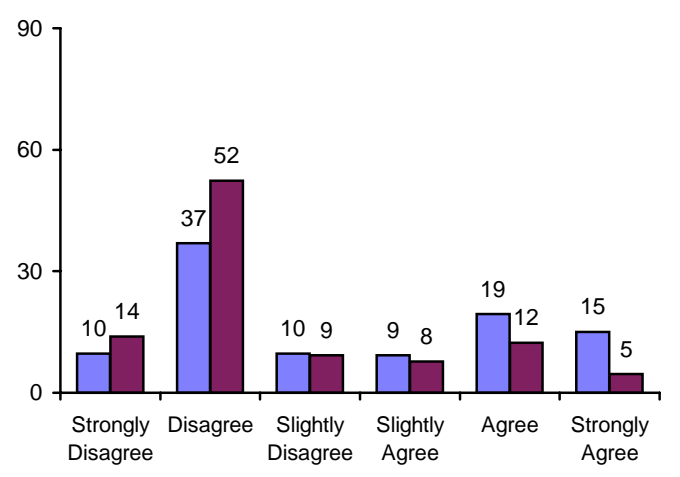

44. It is hard for Alaskan passenger and freight pilots to maintain a consistent sleep schedule.

\begin{tabular}{rrrrccc} 
& \multicolumn{8}{c}{ Descriptive Statistics } \\
& n & Mean & SD & $\%$ Disagree & \% Agree & sig. \\
Non-CFIT Company Pilots & 227 & 3.81 & 1.66 & 31.3 & 43.6 & 2 \\
CFIT Company Pilots & 71 & 3.28 & 1.54 & 46.5 & 26.8 &
\end{tabular}

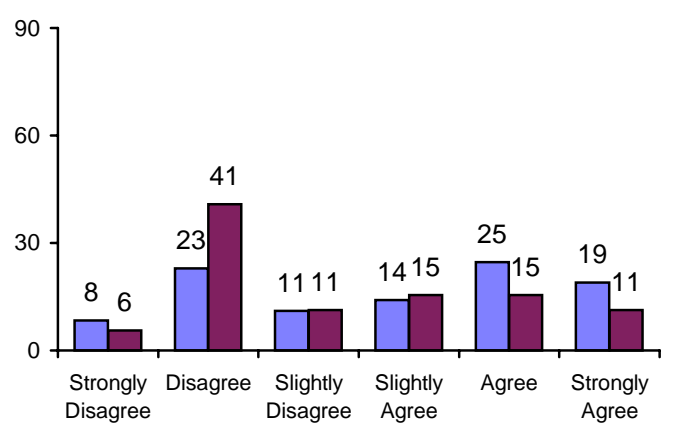

45. In Alaska, during periods of extended daylight, a single-pilot aircrew flies over 8 hours per day.

\begin{tabular}{rrrrcccc} 
& \multicolumn{8}{c}{ Descriptive Statistics } \\
& n & Mean & SD & $\%$ Disagree & $\%$ Agree & sig. \\
Non-CFIT Company Pilots & 198 & 3.17 & 1.61 & 49.0 & 28.3 & 2 \\
CFIT Company Pilots & 67 & 2.61 & 1.34 & 65.7 & 13.4 &
\end{tabular}

\footnotetext{
${ }^{1}$ significant difference (Chi square) $p<.05$

${ }^{2}$ significant difference (Mann-Whitney) $p<.05$

$\%$ Disagree=Strongly Disagree or Disagree

$\%$ Agree $=$ Strongly Agree or Agree
}

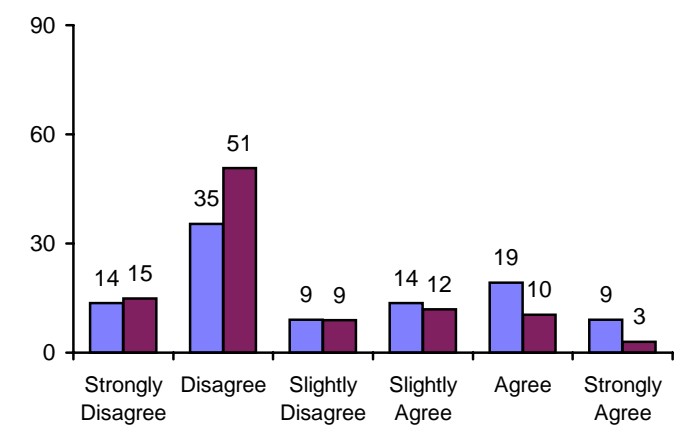


46. Alaskan passenger and freight pilots understand how the time of day can affect their flying performance.

$\begin{array}{rrrrrrrr} & & & & & & \\ & \text { n } & \text { Mean } & \text { SD } & \% \text { Disagree } & \text { \% Agree } & \text { sig. } \\ \text { Non-CFIT Company Pilots } & 227 & 4.58 & 1.13 & 8.8 & 69.6 & 2 \\ \text { CFIT Company Pilots } & 70 & 4.34 & 0.96 & 7.1 & 52.9 & \end{array}$

69. Compared to other Alaskan pilots with similar flying experience, the salary that I receive is:

$\begin{array}{rrrr} & & & \\ & \text { n } & \text { Mean } & \text { SD } \\ \text { Non-CFIT Company Pilots } & 226 & 1.89 & 0.71 \\ \text { CFIT Company Pilots } & 68 & 1.91 & 0.51\end{array}$

Note: Response options were reversed to maintain a consistent direction for scoring.
Alaskan Flight Industry Survey Results Response Distribution (percent)
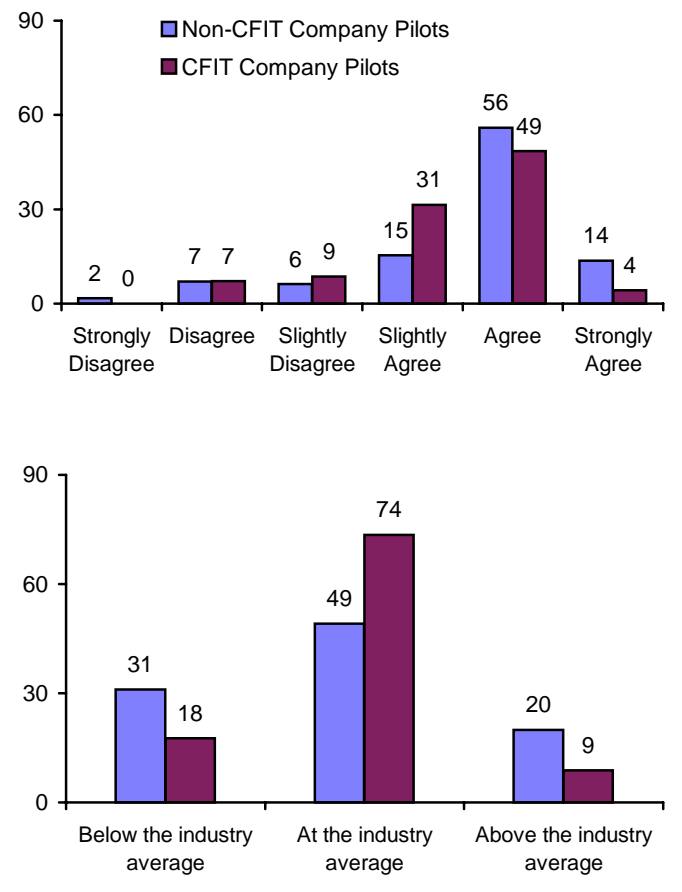

\section{Adverse Psychological States}

19. Over time, being an Alaskan pilot will adversely affect my health.

\begin{tabular}{rrrrccc} 
& \multicolumn{5}{c}{ Descriptive Statistics } \\
& n & Mean & SD & \% Disagree & \% Agree \\
Non-CFIT Company Pilots & 231 & 2.80 & 1.60 & 58.9 & 18.6 \\
CFIT Company Pilots & 71 & 2.87 & 1.59 & 52.1 & 15.5
\end{tabular}

20. As an Alaskan pilot, the job that I perform requires flying in hazardous conditions.

$\begin{array}{rrrrccc} & & & & \\ & \text { n } & \text { Mean } & \text { SD } & \text { \% Disagree } & \text { \% Agree } \\ \text { Non-CFIT Company Pilots } & 230 & 4.53 & 1.46 & 14.8 & 60.4 \\ \text { CFIT Company Pilots } & 71 & 4.63 & 1.31 & 8.5 & 66.2\end{array}$

\footnotetext{
${ }^{1}$ significant difference (Chi square) $p<.05$

${ }^{2}$ significant difference (Mann-Whitney) $p<.05$

$\%$ Disagree=Strongly Disagree or Disagree

$\%$ Agree $=$ Strongly Agree or Agree
}
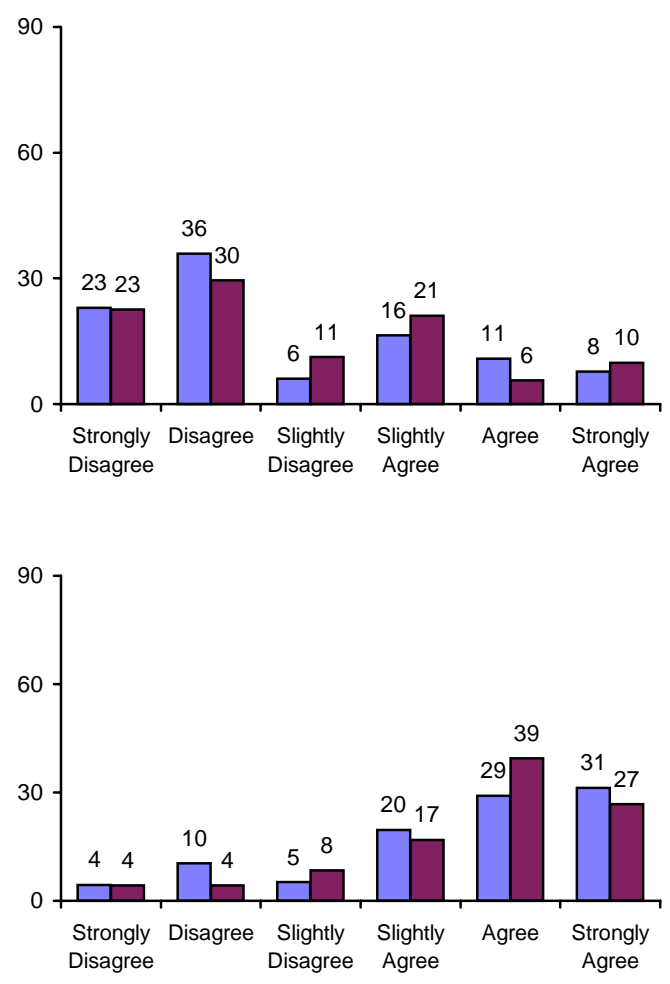
47. Alaskan passenger and freight pilots have to fly sometimes when they are tired.

$\begin{array}{rrrrcc} & & & & \\ & \text { n } & \text { Mean } & \text { SD } & \text { \% Disagree } & \text { \% Agree } \\ \text { Non-CFIT Company Pilots } & 230 & 4.82 & 1.09 & 6.1 & 74.3 \\ \text { CFIT Company Pilots } & 70 & 4.93 & 1.00 & 2.9 & 75.7\end{array}$

48. Alaskan passenger and freight pilots have to fly even when ill.

\begin{tabular}{rrrrccc} 
& \multicolumn{5}{c}{ Descriptive Statistics } \\
& n & Mean & SD & \% Disagree & \% Agree \\
Non-CFIT Company Pilots & 225 & 4.09 & 1.48 & 19.6 & 51.1 \\
CFIT Company Pilots & 70 & 4.10 & 1.25 & 17.1 & 45.7
\end{tabular}

\section{$\underline{\text { Physical/Mental Limitations }}$}

49. Boredom is a problem for Alaskan passenger and freight pilots.

\begin{tabular}{rrrrccc} 
& \multicolumn{6}{c}{ Descriptive Statistics } \\
& n & Mean & SD & \% Disagree & \% Agree \\
Non-CFIT Company Pilots & 229 & 3.10 & 1.43 & 41.5 & 22.7 \\
CFIT Company Pilots & 69 & 3.33 & 1.37 & 33.3 & 24.6
\end{tabular}

50. Unless Alaskan passenger and freight pilots stay on top of the situation, they can soon become overwhelmed with sudden changes in flying conditions.

\begin{tabular}{rrrrccc} 
& \multicolumn{5}{c}{ Descriptive Statistics } \\
& n & Mean & SD & \% Disagree & \% Agree \\
Non-CFIT Company Pilots & 227 & 4.82 & 1.13 & 7.5 & 74.4 \\
CFIT Company Pilots & 69 & 4.90 & 1.11 & 7.2 & 81.2
\end{tabular}

\footnotetext{
${ }^{1}$ significant difference (Chi square) $p<.05$

${ }^{2}$ significant difference (Mann-Whitney) $\mathrm{p}<.05$

$\%$ Disagree $=$ Strongly Disagree or Disagree

$\%$ Agree= Strongly Agree or Agree
}

\section{Response Distribution (percent)}
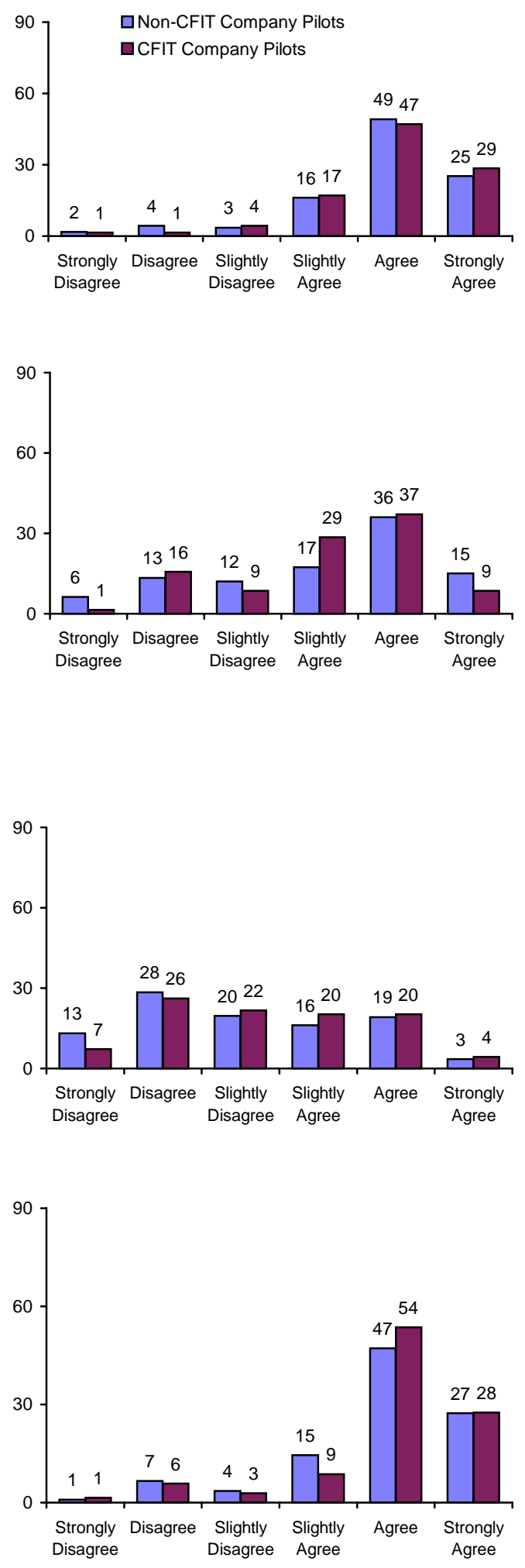


\section{B. Substandard Practices of Operators}

\section{Interpersonal Resource Mismanagement}

81. Rank the following factors based on the amount of pressure created by each to fly in reduced visibility.

a. Delivering the U.S. mail

\begin{tabular}{rrrr} 
& \multicolumn{3}{c}{ Descriptive Statistics } \\
& n & Mean & SD \\
Non-CFIT Company Pilots & 135 & 3.83 & 2.31 \\
CFIT Company Pilots & 51 & 4.00 & 2.07
\end{tabular}

Note: Response options were reversed to maintain a consistent direction for scoring.

b. Company management

\begin{tabular}{rrrr} 
& \multicolumn{3}{c}{ Descriptive Statistics } \\
& n & Mean & SD \\
Non-CFIT Company Pilots & 156 & 5.47 & 1.98 \\
CFIT Company Pilots & 55 & 5.25 & 2.04
\end{tabular}

Note: Response options were reversed to maintain a consistent direction for scoring.

c. Making money for myself

\begin{tabular}{rrrr} 
& \multicolumn{3}{c}{ Descriptive Statistics } \\
& n & Mean & SD \\
Non-CFIT Company Pilots & 148 & 4.68 & 1.99 \\
CFIT Company Pilots & 53 & 4.23 & 2.02
\end{tabular}

Note: Response options were reversed to maintain a consistent direction for scoring.
Response Distribution (percent)
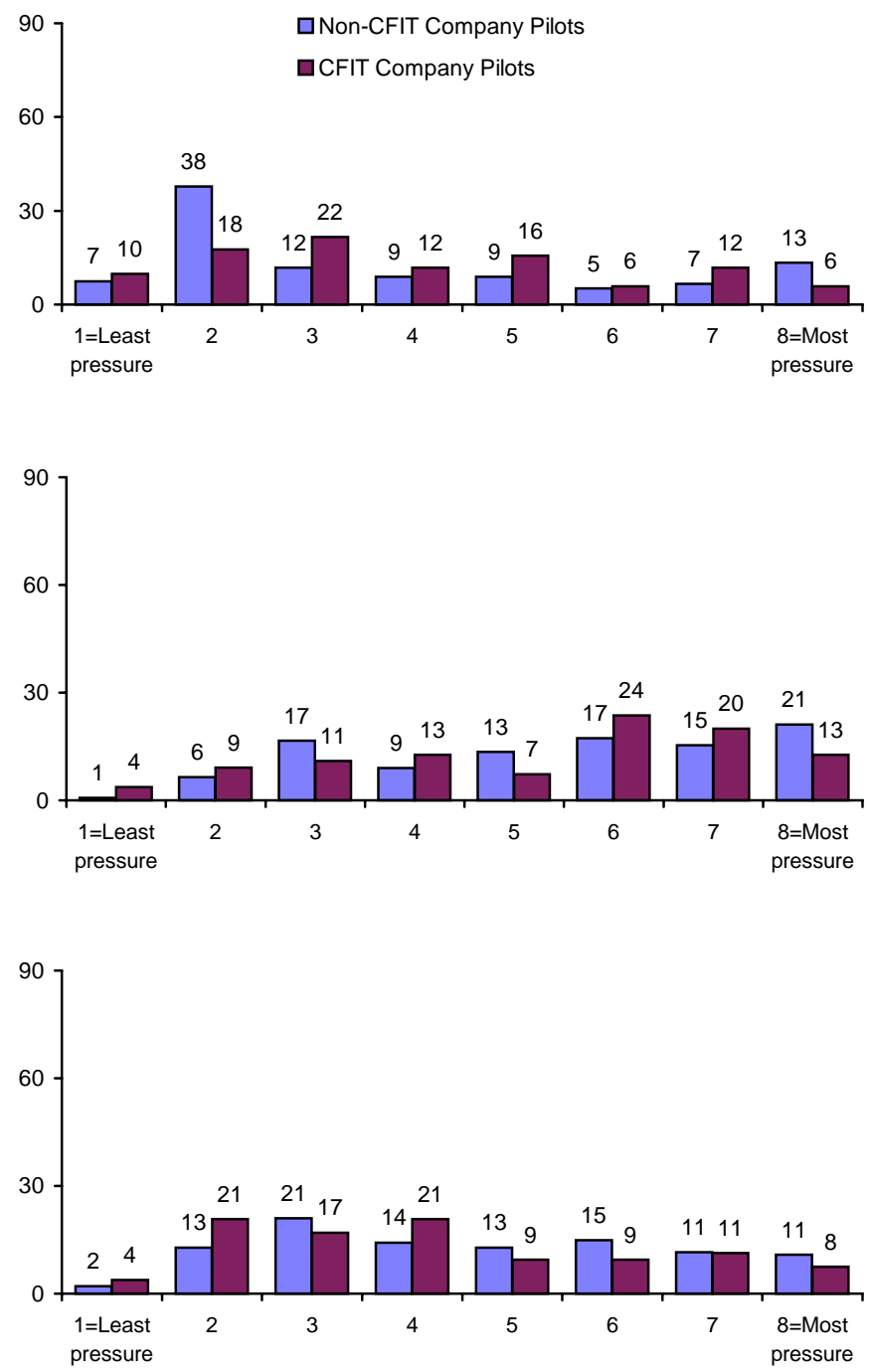

\footnotetext{
${ }^{1}$ significant difference (Chi square) $p<.05$

${ }^{2}$ significant difference (Mann-Whitney) $p<.05$

$\%$ Disagree=Strongly Disagree or Disagree

$\%$ Agree $=$ Strongly Agree or Agree
} 
d. Tight schedule

\begin{tabular}{rrrr} 
& \multicolumn{3}{c}{ Descriptive Statistics } \\
& n & Mean & SD \\
Non-CFIT Company Pilots & 155 & 5.75 & 1.57 \\
CFIT Company Pilots & 53 & 5.30 & 1.51
\end{tabular}

Note: Response options were reversed to maintain a consistent direction for scoring.

e. Peer pressure

\begin{tabular}{rrrr} 
& \multicolumn{3}{c}{ Descriptive Statistics } \\
& n & Mean & SD \\
Non-CFIT Company Pilots & 153 & 4.63 & 1.75 \\
CFIT Company Pilots & 52 & 4.63 & 1.94
\end{tabular}

Note: Response options were reversed to maintain a consistent direction for scoring.

f. Pride in my ability

\begin{tabular}{rrrr} 
& \multicolumn{3}{c}{ Descriptive Statistics } \\
& n & Mean & SD \\
Non-CFIT Company Pilots & 156 & 5.21 & 1.93 \\
CFIT Company Pilots & 55 & 4.96 & 2.14
\end{tabular}

Note: Response options were reversed to maintain a consistent direction for scoring.

g. Passengers

\begin{tabular}{rrrr} 
& \multicolumn{3}{c}{ Descriptive Statistics } \\
& n & Mean & SD \\
Non-CFIT Company Pilots & 149 & 5.56 & 2.03 \\
CFIT Company Pilots & 53 & 5.62 & 2.28
\end{tabular}

Note: Response options were reversed to maintain a consistent direction for scoring.

\section{Response Distribution (percent)}
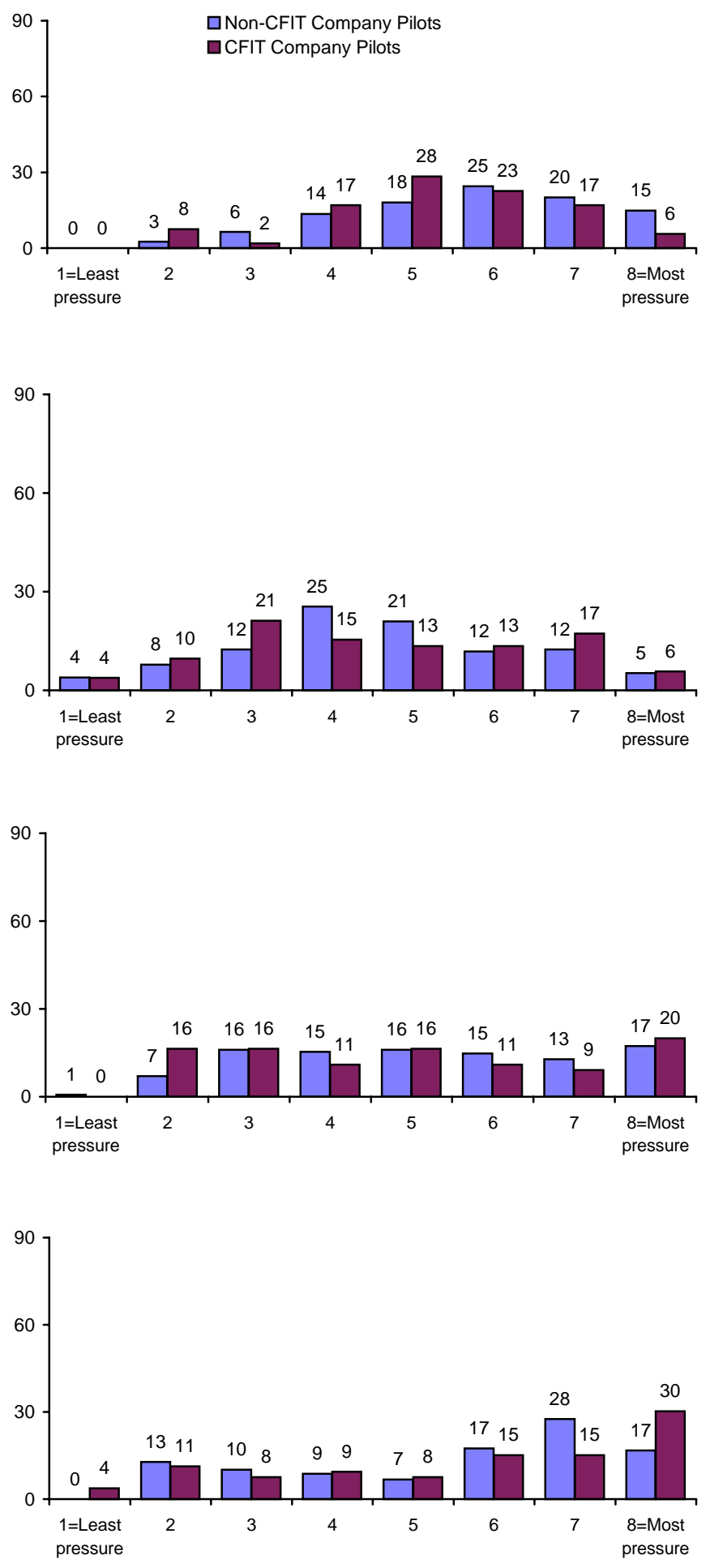

\footnotetext{
${ }^{1}$ significant difference (Chi square) $p<.05$

${ }^{2}$ significant difference (Mann-Whitney) $p<.05$

$\%$ Disagree=Strongly Disagree or Disagree

$\%$ Agree $=$ Strongly Agree or Agree
} 
h. other reasons for flying in reduced visibility

$\begin{array}{rrrrr} & & & & \\ & \text { n } & \text { Mean } & \text { SD } \\ \text { Non-CFIT Company Pilots } & 42 & 5.79 & 3.09 \\ \text { CFIT Company Pilots } & 17 & 5.35 & 3.39\end{array}$

Note: Response options were reversed to maintain a consistent direction for scoring.

\section{Response Distribution (percent)}

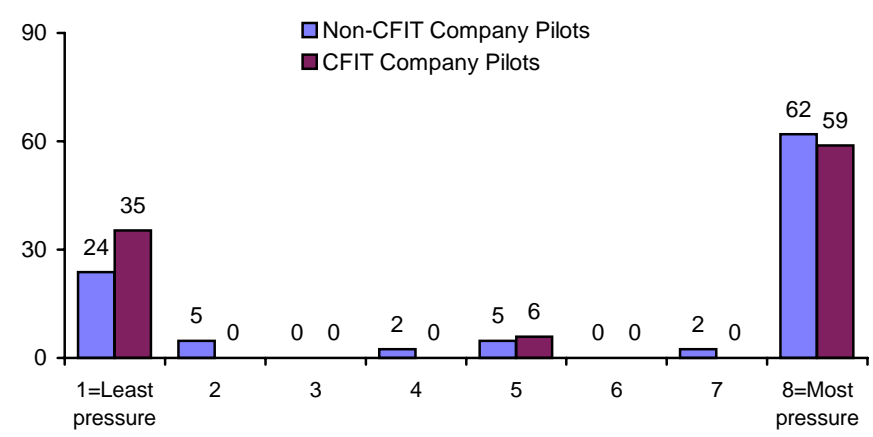

\section{Personal Readiness}

Please indicate the certificate holders you work for:

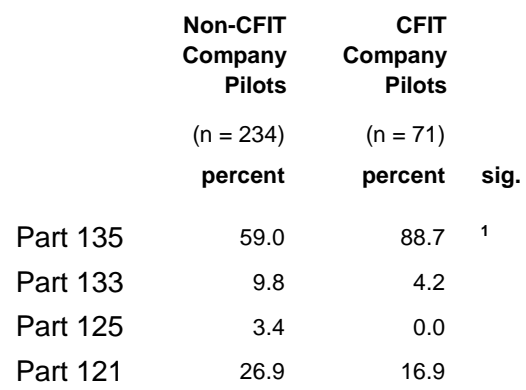

51. In Alaska, it is possible to eliminate all accidents caused by passenger and freight pilots flying into terrain in poor weather.

\begin{tabular}{rrrrccc} 
& \multicolumn{5}{c}{ Descriptive Statistics } \\
& $\mathbf{n}$ & Mean & SD & \% Disagree & \% Agree \\
Non-CFIT Company Pilots & 228 & 4.11 & 1.50 & 21.1 & 49.6 \\
CFIT Company Pilots & 69 & 4.01 & 1.47 & 20.3 & 43.5
\end{tabular}

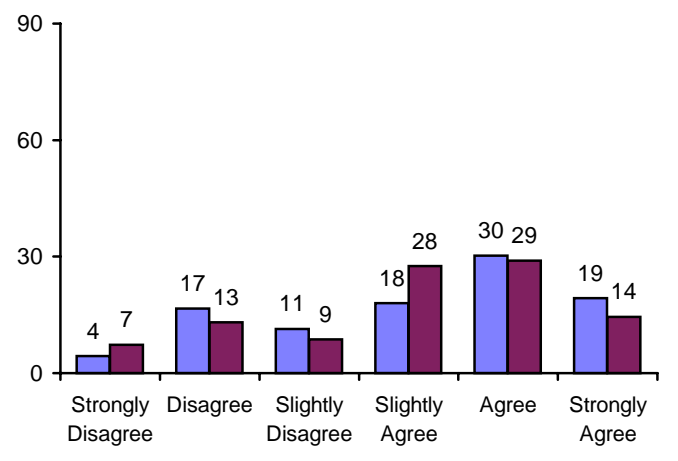

70. I am years old.

Non-CFIT Company Pilots

CFIT Company Pilots

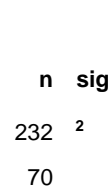

70

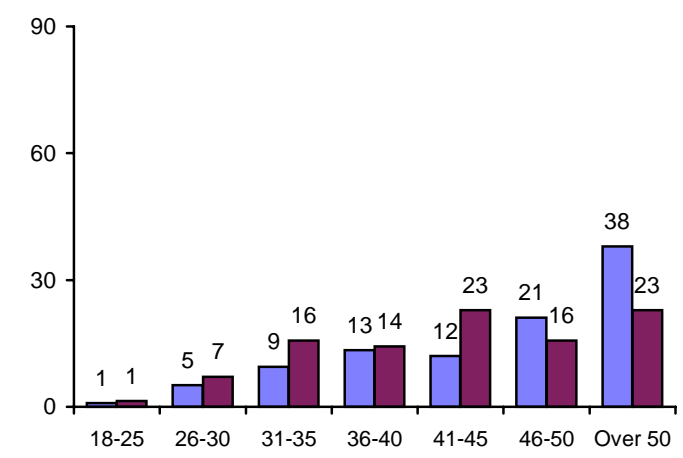

\footnotetext{
${ }^{1}$ significant difference (Chi square) $p<.05$

${ }^{2}$ significant difference (Mann-Whitney) $\mathrm{p}<.05$

$\%$ Disagree=Strongly Disagree or Disagree

$\%$ Agree= Strongly Agree or Agree
} 
71. I've flown in Alaska a total of years (round to the nearest year).

$\begin{array}{rrrrr} & & & & \\ & n & \text { Mean } & \text { SD } & \text { sig. } \\ \text { Non-CFIT Company Pilots } & 233 & 18.56 & 10.38 & 2 \\ \text { CFIT Company Pilots } & 70 & 15.07 & 10.47 & \end{array}$

72. I fly in Alaska during the following months (choose all that apply):

\section{Mean Years}

$\square$ Non-CFIT Company Pilots

口CFIT Company Pilots

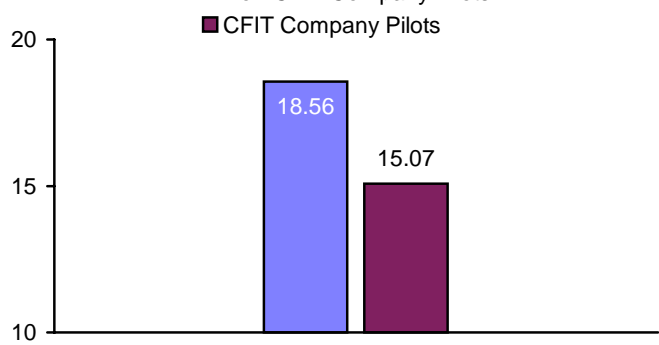

$\begin{array}{lrrrr} & \begin{array}{r}\text { Non-CFIT } \\ \text { Company } \\ \text { Pilots }\end{array} & \begin{array}{r}\text { CFIT } \\ \text { Company } \\ \text { Pilots }\end{array} & \\ & \begin{array}{l}\mathrm{n}=234) \\ \text { percent }\end{array} & \begin{array}{r}(\mathrm{n}=71) \\ \text { percent }\end{array} & \text { sig. } \\ & 83.3 & 95.8 & \mathbf{1} \\ \text { a. January } & 84.2 & 95.8 & \mathbf{1} \\ \text { b. February } & 87.6 & 94.4 & \\ \text { c. March } & 91.9 & 95.8 & \\ \text { d. April } & 95.3 & 98.6 & \\ \text { e. May } & 95.3 & 97.2 & \\ \text { f. June } & 94.0 & 97.2 & \\ \text { g. July } & 93.2 & 97.2 & \\ \text { h. August } & 97.9 & 98.6 & \\ \text { i. September } & 92.3 & 97.2 & \\ \text { j. October } & 85.5 & 97.2 & \mathbf{1} \\ \text { k. November } & 82.9 & 95.8 & \mathbf{1} \\ \text { I. December } & & & \end{array}$

73. My total number of non commercial $A / C$ hours flown in Alaska is:

a. non commercial fixed wing hours

Mean Hours

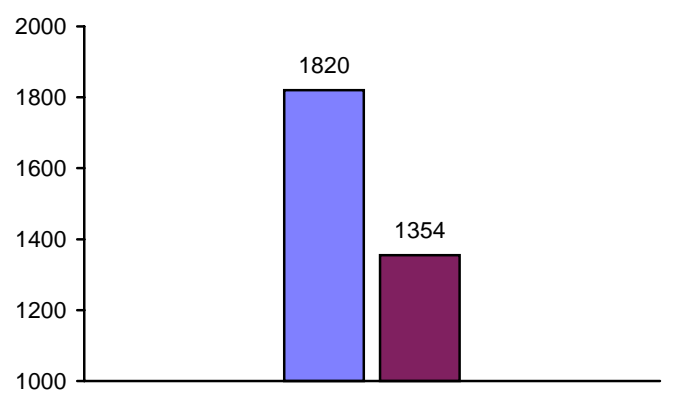

\footnotetext{
${ }^{1}$ significant difference (Chi square) $p<.05$

${ }^{2}$ significant difference (Mann-Whitney) $p<.05$

$\%$ Disagree=Strongly Disagree or Disagree

$\%$ Agree $=$ Strongly Agree or Agree
} 
b. non commercial rotary hours

\begin{tabular}{rrrr} 
& \multicolumn{3}{c}{ Descriptive Statistics } \\
& n & Mean & SD \\
Non-CFIT Company Pilots & 79 & 420 & 1336 \\
CFIT Company Pilots & 27 & 78 & 187
\end{tabular}

74. My total number of commercial $\mathrm{A} / \mathrm{C}$ hours flown in Alaska is:

a. commercial fixed wing hours

\begin{tabular}{rrrr} 
& \multicolumn{3}{c}{ Descriptive Statistics } \\
& n & Mean & SD \\
Non-CFIT Company Pilots & 214 & 7046 & 6646 \\
CFIT Company Pilots & 68 & 6886 & 6550
\end{tabular}

b. commercial rotary hours

\begin{tabular}{rrrrl} 
& \multicolumn{4}{c}{ Descriptive Statistics } \\
& n & Mean & SD & sig. \\
Non-CFIT Company Pilots & 80 & 2970 & 4195 & 2 \\
CFIT Company Pilots & 28 & 1129 & 2611 &
\end{tabular}

75. I hold the following airman's certificates and ratings (choose all that apply):

\section{Mean Hours}

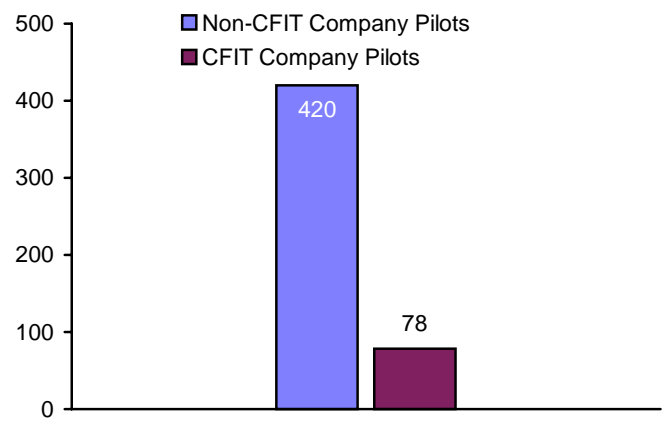

Mean Hours

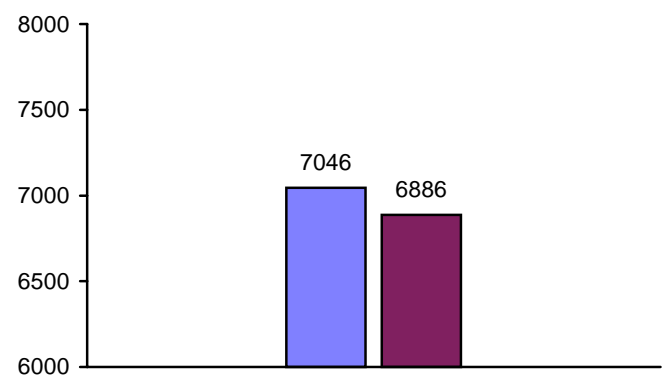

Mean Hours

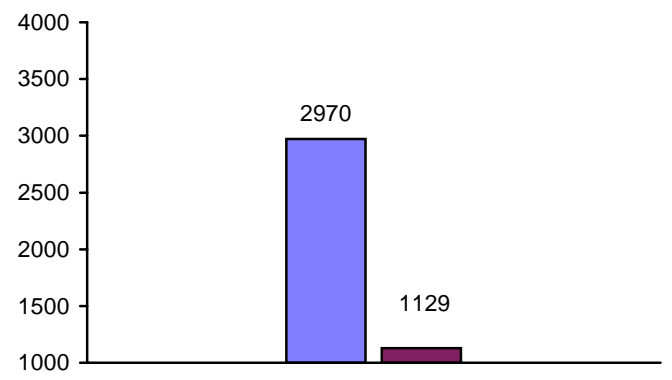

\footnotetext{
${ }^{1}$ significant difference (Chi square) $p<.05$

${ }^{2}$ significant difference (Mann-Whitney) $p<.05$

$\%$ Disagree=Strongly Disagree or Disagree

$\%$ Agree $=$ Strongly Agree or Agree
}

\begin{abstract}
a. Commercial
b. Airline Transport Pilot
\end{abstract}

$\begin{array}{rrr}\begin{array}{r}\text { Non-CFIT } \\ \text { Company } \\ \text { Pilots }\end{array} & \begin{array}{r}\text { Company } \\ \text { Pilots }\end{array} \\ (\mathrm{n}=234) & (\mathrm{n}=71) & \\ \text { percent } & \text { percent } & \text { sig. } \\ 64.53 & 57.75 & \\ 61.54 & 80.28 & 1\end{array}$


76. I attend pilot safety meetings of some kind:

$$
\text { Non-CFIT Company Pilots }
$$$$
\text { CFIT Company Pilots }
$$$$
\begin{array}{r}
\mathbf{n} \\
215 \\
56
\end{array}
$$

n

56

82. My permanent residence is in Alaska.

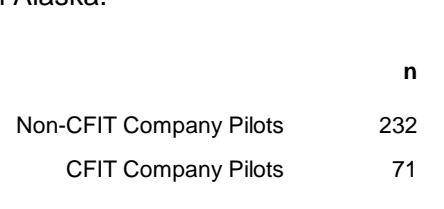

Alaskan Flight Industry Survey Results Response Distribution (percent)
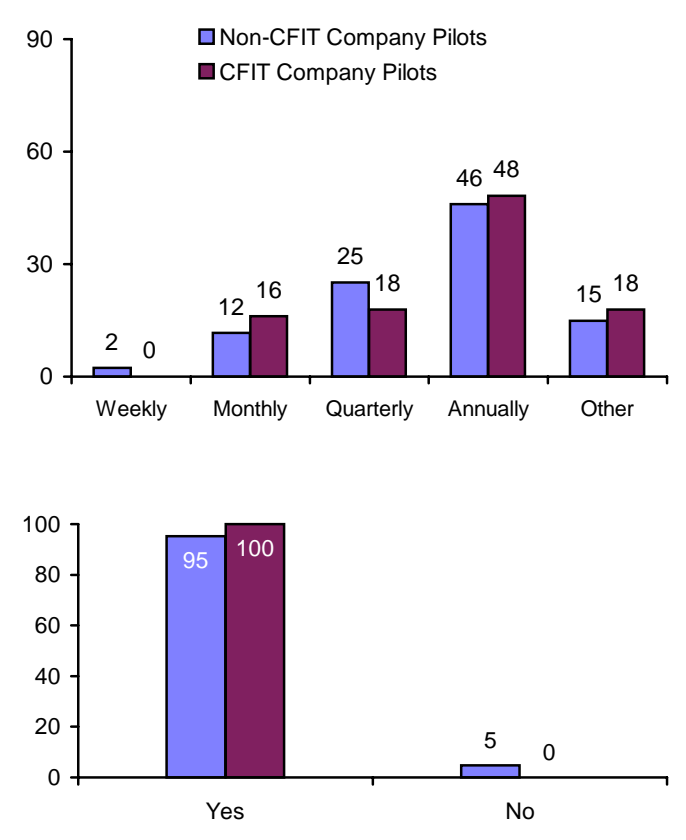

\section{UNSAFE ACTS}

\section{A. Errors}

\section{Decision Error}

52. It is safe for Alaskan passenger and freight pilots to fly under low-lying narrow bands of clouds, provided that the visibility is clear beneath the clouds and it looks clear beyond the cloudy area.

\begin{tabular}{rrrrcc} 
& \multicolumn{5}{c}{ Descriptive Statistics } \\
& n & Mean & SD & \% Disagree & \% Agree \\
Non-CFIT Company Pilots & 220 & 4.30 & 1.17 & 11.4 & 56.8 \\
CFIT Company Pilots & 69 & 4.32 & 1.02 & 11.6 & 58.0
\end{tabular}

53. Passenger and freight pilots in Alaska are more likely to "push" the weather when aircraft are equipped with modern navigation equipment.

\begin{tabular}{rrrrcc} 
& \multicolumn{5}{c}{ Descriptive Statistics } \\
& n & Mean & SD & \% Disagree & \% Agree \\
Non-CFIT Company Pilots & 222 & 4.21 & 1.29 & 15.3 & 52.7 \\
CFIT Company Pilots & 69 & 4.39 & 1.05 & 8.7 & 55.1
\end{tabular}
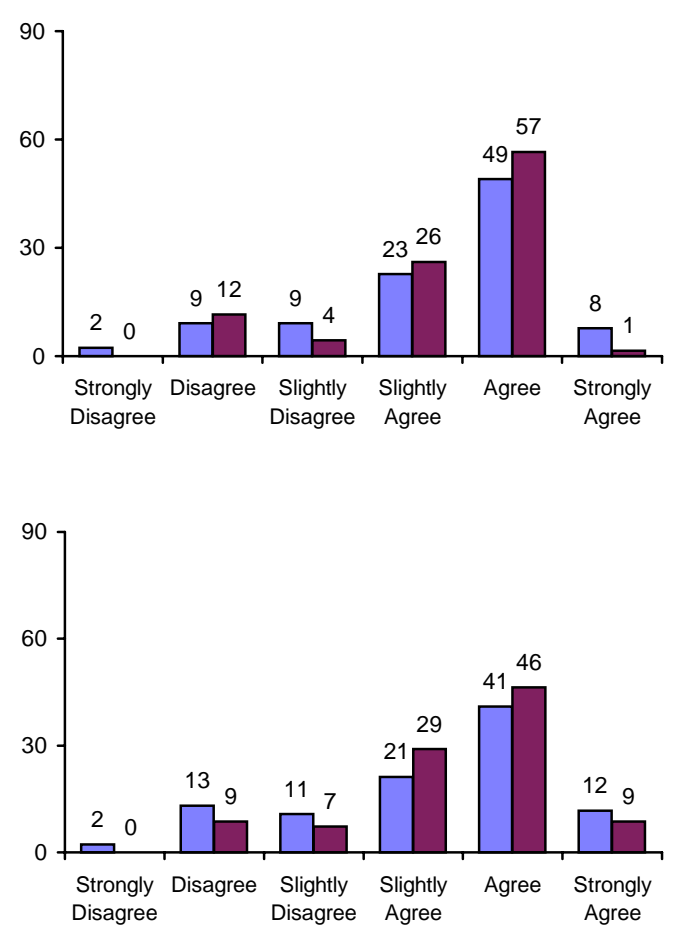

\footnotetext{
${ }^{1}$ significant difference (Chi square) $p<.05$

${ }^{2}$ significant difference (Mann-Whitney) $p<.05$

$\%$ Disagree=Strongly Disagree or Disagree

$\%$ Agree $=$ Strongly Agree or Agree
} 
54. In Alaska, "rules of thumb" learned from more experienced passenger and freight pilots are required in order to fly through areas of low clouds and reduced visibility.

\begin{tabular}{rrrrcc} 
& \multicolumn{5}{c}{ Descriptive Statistics } \\
& n & Mean & SD & \% Disagree & $\%$ Agree \\
Non-CFIT Company Pilots & 220 & 3.80 & 1.38 & 23.6 & 38.2 \\
CFIT Company Pilots & 67 & 4.01 & 1.30 & 10.4 & 37.3
\end{tabular}

55. Flying under VFR in low visibility conditions over hills and mountains is a common experience for Alaskan passenger and freight pilots.

\begin{tabular}{rrrrccc} 
& \multicolumn{5}{c}{ Descriptive Statistics } \\
& n & Mean & SD & \% Disagree & $\%$ Agree \\
Non-CFIT Company Pilots & 216 & 4.12 & 1.36 & 18.1 & 51.4 \\
CFIT Company Pilots & 69 & 4.22 & 1.19 & 14.5 & 50.7
\end{tabular}

\section{B. Violations}

\section{$\underline{\text { Routine }}$}

56. For Alaskan passenger and freight operations, it is considered safe to fly VMC in visibility below 1 mile on routes over which the pilot has flown many times before.

\begin{tabular}{rrrrcc} 
& \multicolumn{5}{c}{ Descriptive Statistics } \\
& n & Mean & SD & \% Disagree & \% Agree \\
Non-CFIT Company Pilots & 218 & 3.06 & 1.48 & 45.9 & 22.5 \\
CFIT Company Pilots & 69 & 2.87 & 1.28 & 49.3 & 15.9
\end{tabular}

57. In Alaska, it is safe for passenger and freight pilots to fly VMC en route when visibility is less than 1 mile, provided that pilots know the destination weather is good.

\begin{tabular}{rrrrcc} 
& \multicolumn{5}{c}{ Descriptive Statistics } \\
& n & Mean & SD & \% Disagree & \% Agree \\
Non-CFIT Company Pilots & 221 & 2.59 & 1.31 & 59.7 & 12.2 \\
CFIT Company Pilots & 69 & 2.52 & 1.22 & 62.3 & 8.7
\end{tabular}

\footnotetext{
${ }^{1}$ significant difference (Chi square) $p<.05$

${ }^{2}$ significant difference (Mann-Whitney) $p<.05$

$\%$ Disagree=Strongly Disagree or Disagree

$\%$ Agree $=$ Strongly Agree or Agree
}

\section{Response Distribution (percent)}

Alaskan Flight Industry Survey Results
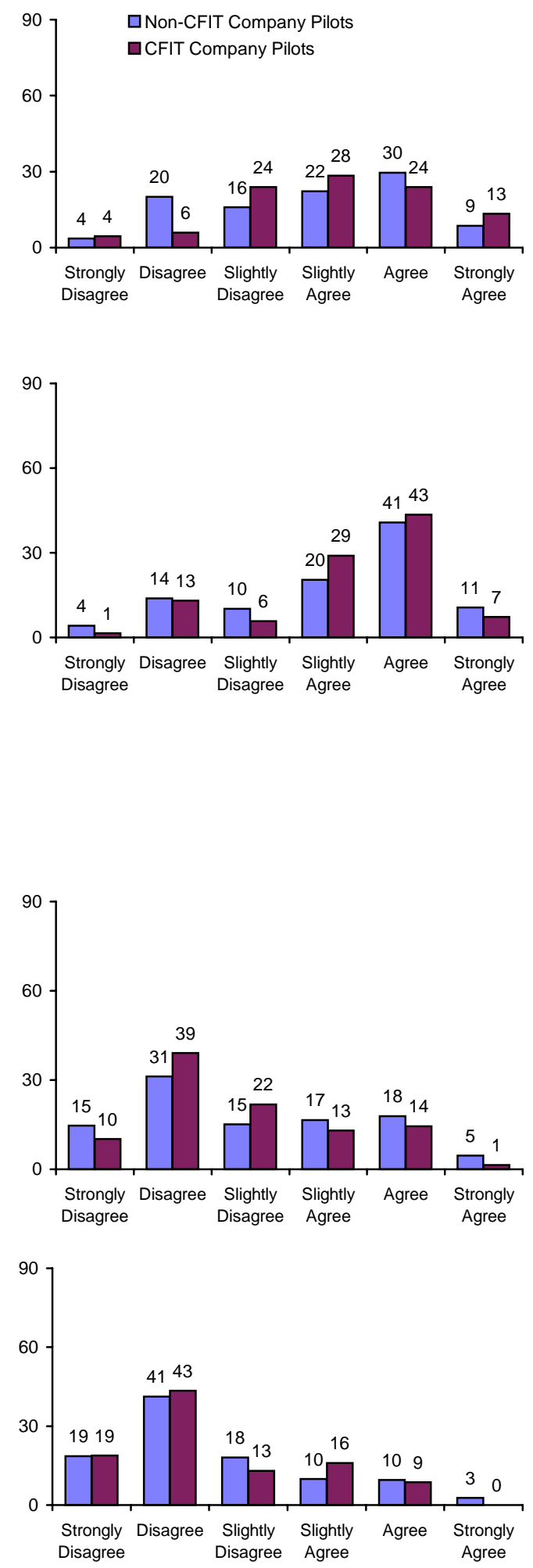
58. It is okay for Alaskan passenger and freight pilots to fly in weather below 500 -foot ceilings and 1 -mile visibility as long as the pilot feels it can be done safely.

\begin{tabular}{rrrrcc} 
& \multicolumn{5}{c}{ Descriptive Statistics } \\
& n & Mean & SD & \% Disagree & \% Agree \\
Non-CFIT Company Pilots & 220 & 2.77 & 1.53 & 59.1 & 20.9 \\
CFIT Company Pilots & 70 & 2.51 & 1.39 & 64.3 & 15.7
\end{tabular}

77. When flying VMC over mountains, I would turn around when the visibility is reduced to:

Non-CFIT Company Pilots

$n$
212
62

78. When flying VMC over flat terrain, I would turn around when the visibility is reduced to:

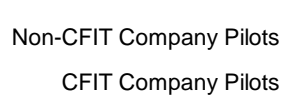

$n$
215
65

\footnotetext{
${ }^{1}$ significant difference (Chi square) $p<.05$

${ }^{2}$ significant difference (Mann-Whitney) $p<.05$

$\%$ Disagree $=$ Strongly Disagree or Disagree

$\%$ Agree= Strongly Agree or Agree
}

Alaskan Flight Industry Survey Results Response Distribution (percent)
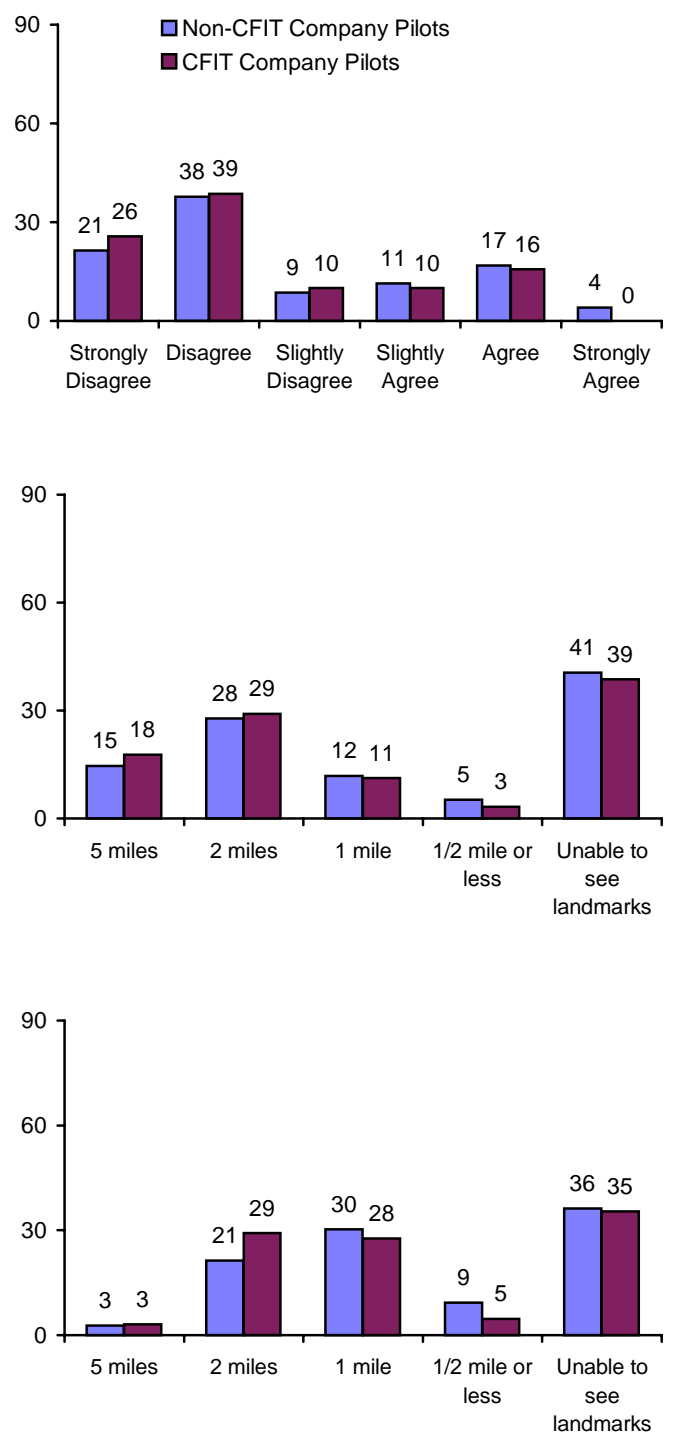